\title{
Contaminação na Baía de Todos os Santos
}

\author{
da Rocha, G. O.;* Guarieiro, A. L. N.; de Andrade, J. B.; Eça, G. F.; de \\ Aragão, N. M.; Aguiar, R. M.; Korn, M. G. A.; Brito, G. B.; Moura, C. W. N.; \\ Hatje, $\mathrm{V}$.
}

Rev. Virtual Quim., 2012, 4 (5), 583-610. Data de publicação na Web: 10 de Outubro de 2012

\author{
http://www.uff.br/rvq
}

\section{Contamination at Todos os Santos Bay}

Abstract: Todos os Santos Bay (BTS) is the second largest coastal bay in Brazil, which occupies an area of $1,233 \mathrm{~km}^{2}$ and $184 \mathrm{~km}$ of coastline perimeter. The BTS includes an urban area, including Salvador, with more than 3 million inhabitants and an extensive industrial area. This paper focuses on the chemical contamination of the atmosphere and marine coastal system of BTS, discussing the main sources of different compounds found. In several regions of the BTS atmospheric particulate matter, suspended particulate matter, algae, sediment and biota are enriched with trace elements ( $\mathrm{As}, \mathrm{Cd}, \mathrm{Pb}, \mathrm{Zn}, \mathrm{Hg}, \mathrm{Mn}$, $\mathrm{Co}, \mathrm{Cu}, \mathrm{Sb}$, among others) and organic contaminants (PAH and $\mathrm{n}$-alkanes) at concentration levels above those considered "natural". Therefore, anthropogenic contributions (industrial discharges and domestic oil and gas extraction, power generation processes, vehicular emission and port activities) contributed to the environmental levels of contaminants studied to date.

Keywords: Contaminants; metals; hydrocarbons; atmosphere; sediments; biota; Todos os Santos Bay.

\section{Resumo}

A Baía de Todos os Santos (BTS) é a segunda maior baía costeira do Brasil, em que ocupa uma área de $1.233 \mathrm{~km}^{2}$ e $184 \mathrm{~km}$ de perímetro de costa. O entorno da BTS compreende uma área urbana, incluindo Salvador, com mais de 3 milhões de habitantes e uma extensa zona industrial. $O$ foco deste trabalho está sobre a contaminação química da atmosfera e do sistema costeiro marinho da BTS, discutindo as principais fontes de diferentes compostos encontrados. Em várias regiões da BTS o material particulado atmosférico, material particulado em suspensão, sedimentos e biota encontram-se enriquecidos por elementos traço ( $\mathrm{As}, \mathrm{Cd}, \mathrm{Pb}, \mathrm{Zn}, \mathrm{Hg}, \mathrm{Mn}, \mathrm{Co}, \mathrm{Cu}, \mathrm{Sb}$, dentre outros) e por contaminantes orgânicos ( $\mathrm{n}$ alcanos e HPA) em níveis de concentração acima do considerado "natural". Logo, as contribuições antrópicas (descargas de efluentes industriais e domésticos, extração de petróleo e gás, processos de geração de energia, emissão veicular e atividades portuárias) contribuíram para os níveis ambientais dos contaminantes estudados até o presente momento.

Palavras-chave: Contaminantes; metais; hidrocarbonetos; atmosfera; sedimento; biota; Baía de Todos os Santos.

\footnotetext{
* Universidade Federal da Bahia, Instituto de Química, 40170-290, Salvador, BA, Brasil e INCT Energia e Ambiente, UFBA. 40170-290, Salvador, BA, Brasil.

$M$ giseleor@pq.cnpq.br

DOI: 10.5935/1984-6835.20120045
} 


\section{Contaminação na Baía de Todos os Santos}

\section{Gisele O. da Rocha, ${ }^{a, b, *}$ Aline L. N. Guarieiro, ${ }^{b}$ Jailson B. de Andrade, ${ }^{a, b}$ Gilmara F. Eça, ${ }^{\mathrm{a}}$ Nádia M. Aragão, ${ }^{\mathrm{C}}$ Rosane M. Aguiar, ${ }^{\mathrm{C}}$ Maria das Graças A. Korn, ${ }^{\mathrm{a}, \mathrm{b}}$ Geysa B. Brito, ${ }^{\mathrm{a}}$ Carlos W. N. Moura, ${ }^{\mathrm{d}}$ Vanessa Hatje ${ }^{\mathrm{a}, \mathrm{b}}$}

a Universidade Federal da Bahia, Instituto de Química, 40170-290, Salvador, BA, Brasil.

bINCT de Energia e Ambiente, UFBA. 40170-290, Salvador, BA, Brasil.

'Universidade Estadual do Sudoeste da Bahia, Departamento de Química, 45200-000, Jequié, BA, Brasil.

'Universidade Estadual de Feira de Santana, Laboratório de Ficologia, Av. Transnordestina, s/n, Novo Horizonte, 44036-900, Feira de Santana, Bahia, Brasil.

*giseleor@pq.cnpq.br

Recebido em 30 de agosto de 2012. Aceito para publicação em 24 de setembro de 2012

\section{Introdução}

2. Principais contaminantes da atmosfera

\section{Principais contaminantes da hidrosfera}

3.1. Material particulado em suspensão e em sedimentos

3.2. Bivalves

3.3. Algas

\section{Conclusões}

\section{Introdução}

A eliminação de resíduos pelas indústrias, a queima de combustíveis fósseis, processos de geração de energia, a emissão de efluentes industriais e domésticos, queima de biomassa, lixo doméstico e as atividades de mineração são exemplos de fontes geradoras de contaminação que afetam os três grandes reservatórios do planeta: a hidrosfera, a litosfera e a atmosfera. O esforço para resolver os problemas ambientais requer a compreensão dos processos químicos que ocorrem na água, ar, sedimentos, bem como os processos químicos ambientais que ocorrem na biota. ${ }^{1,2}$

A atmosfera constitui um importante meio de transporte e depósito para as substâncias orgânicas e inorgânicas emitidas por fontes tanto naturais quanto antrópicas. Ao chegarem à atmosfera esses compostos começam a sofrer transformações químicas e fotoquímicas. Mecanismos de remoção de contaminantes atmosféricos tais como a deposição seca e a deposição úmida podem constituir uma importante rota de contaminantes químicos para outros compartimentos ambientais, tais como sistemas aquáticos e solo. ${ }^{3}$ Por sua vez, Rev. Virtual Quim. |Vol 4| |No. 5| |583-610| 
quando os contaminantes alcançam os sistemas aquáticos, dependendo de suas características físico-químicas e as subsequentes transformações físicas, biológicas e químicas que podem sofrer, irão fatalmente se distribuir entre as águas, material particulado em suspensão, sedimentos e biota. Ainda, em regiões costeiras, a interação entre o ambiente marinho e o continente é incontestável.

A Baía de Todos os Santos, localizada no estado da Bahia, entre coordenadas $08^{\circ} 30^{\prime} \mathrm{e}$ $18^{\circ} 30^{\prime} \mathrm{S}$ e $37^{\circ} 30^{\prime}$ e $46^{\circ} 30^{\prime} \mathrm{W}$ (figura 1 ), é a segunda maior baía costeira do Brasil, em que ocupa uma área de $1.233 \mathrm{~km}^{2}$ e $184 \mathrm{~km}$ de perímetro de costa. O entorno da Baía de Todos os Santos (BTS) compreende uma área urbana, incluindo Salvador, com mais de 3 milhões de habitantes e uma extensa zona industrial. A baía também é vizinha a Base Naval de Aratu e ao maior polo petroquímico do hemisfério sul. Reservas de óleo e gás são exploradas na plataforma interna a menos de $100 \mathrm{~km}$ da entrada da baía. ${ }^{4}$

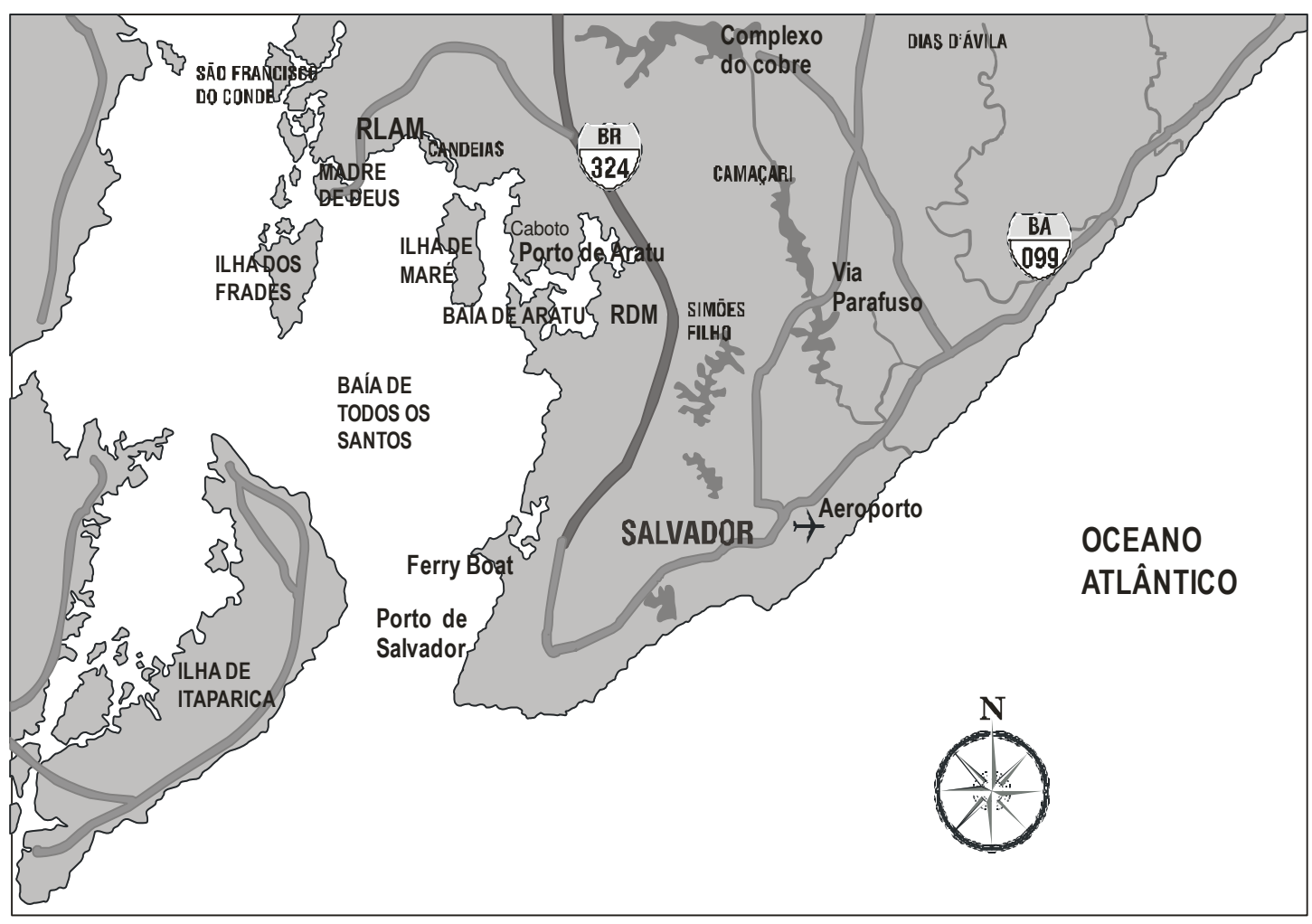

Figura 1. Mapa da Baía de Todos os Santos, BA, Brasil

Desde o inicio da sua ocupação, foram implantados usos múltiplos dos recursos naturais da Baía. Todavia, o crescimento industrial da região foi iniciado basicamente na década de 30, quando da descoberta e início da exploração do petróleo, que terminou por conduzir o Governo do Estado da Bahia, nas décadas de 1960 e 1970, à opção pelo desenvolvimento petroquímico como modelo de desenvolvimento econômico do Estado. O maior número de indústrias no Recôncavo baiano está concentrado nos municípios de Simões Filho, Feira de Santana e Candeias, localizados a nordeste, noroeste e norte da BTS, respectivamente. As principais atividades industriais desenvolvidas são: químicas, petroquímicas, metalúrgicas, de produtos alimentícios e fertilizantes. Os produtos químicos utilizados por estas indústrias são diversos e incluem metais (Fe, $\mathrm{Zn}, \mathrm{Hg}, \mathrm{Mn}$ e $\mathrm{Cu})$, ácidos minerais, sulfetos e sulfatos metálicos, óleos vegetais, petróleo e derivados, soda, naftaleno, benzeno, fenol, 
polipropileno, cloro, hexano, óxidos, celulose, sisal, brita e amônia, dentre outros. ${ }^{5}$

O cenário atual do ambiente natural e as ocupações humanas no entorno da baía possuem gradientes físicos e sociais diferenciados, de acordo com as dificuldades de acesso e de infraestrutura disponíveis. Além disso, derrames de petróleo e seus derivados através de acidentes ou de vazamentos operacionais, além da degradação da qualidade das águas por efluentes domésticos e industriais, e drenagens, dentre outros, contribuíram para agravar a situação dos diferentes ecossistemas da Baía de Todos os Santos com alterações na vida aquática, na composição química da atmosfera, na saúde humana e na qualidade de vida das populações ribeirinhas. ${ }^{6}$ Entretanto, muito pouco foi até hoje estudado sobre a Baía de Todos os Santos.

O presente artigo visa apresentar e discutir tópicos sobre a contaminação química da atmosfera e do sistema costeiro marinho da BTS, discutindo as principais fontes de diferentes compostos encontrados. Para tanto, são apresentados resultados sobre contaminantes inorgânicos e orgânicos no material particulado em suspensão, material particulado atmosférico, sedimentos, algas e bivalves.

\section{Principais contaminantes da atmosfera}

O material particulado atmosférico (MPA) geralmente é emitido por diferentes fontes, a maior parte delas relacionadas à atividade humana. ${ }^{7} \mathrm{~A}$ atmosfera é o principal veículo para o movimento e redistribuição de poluentes, e o meio em que quase todos se apresentam é no material particulado (MP). Os tempos de residência do MP na atmosfera são geralmente de curta duração (inferior a 40 dias), dependendo do seu tamanho aerodinâmico e padrões climáticos e meteorológicos de uma dada região. Além disso, devem ser considerados os processos de transporte de MP que podem causar perturbações nos ecossistemas em escala local, regional ou até mesmo global. ${ }^{8}$

Vários estudos apontam que a fração de tamanho de partícula e a sua composição química como dois importantes aspectos a serem considerados, muito associados a uma grande variedade de efeitos adversos para a saúde humana. ${ }^{9-11}$ Enquanto a composição química do MPA pode variar de um lugar para outro, as fontes de material particulado são numerosas e diversas para uma dada região em estudo, podendo estas ser biogênicas (principalmente emissão de partículas por vegetais, ressuspensão do solo e spray marinho) ou antrópicas (emissão industrial, emissão portuária, queima de combustíveis fósseis, queima de biomassa, incineração de resíduos e processos para a geração de energia). ${ }^{12-14}$ Os contaminantes presentes no MPA podem ser inorgânicos (elementos traço e espécies iônicas, por exemplo), orgânicos (diversas classes de substâncias orgânicas) e/ou radioativos. Os principais processos de remoção de partículas na atmosfera são a deposição seca e a deposição úmida.

Nos últimos anos, houve um aumento no interesse pelos processos de deposição atmosférica, já que esse mecanismo desempenha um papel fundamental para a transferência de poluentes da atmosfera para a superfície do solo ou de corpos d'água. Embora as fontes de metais e HPA para o solo e a água sejam diversas e muitas delas ainda pouco estabelecidas, acredita-se que a deposição atmosférica seja um importante mecanismo, com destaque para os mecanismos de deposição seca.

A atmosfera da BTS recebe influência de fontes antrópicas (emissão industrial, emissão veicular, etc.) provenientes do Polo Petroquímico de Camaçari, Centro Industrial de Aratu, Região Metropolitana de Salvador, Porto de Aratu e Porto de Salvador bem como de fontes biogênicas (emissão pela vegetação, emissão marinha, ressuspensão de partículas, etc.). Existem estudos ainda

Rev. Virtual Quim. |Vol 4| |No.5| |583-610| 
escassos sobre a atmosfera da Baía de Todos os Santos, ${ }^{12-16}$ e ainda sabe-se pouco ou muito pouco sobre a química atmosférica da região. A seguir são apresentados e discutidos alguns estudos sobre elementos traço e HPA no material particulado atmosférico da BTS.

\section{Elementos traço}

Em estudo desenvolvido na Baía de Todos os Santos por Pereira et al. ${ }^{14}$ foram investigadas as concentrações atmosféricas de Fe, Mn, Cu e Zn presentes nas frações PTS (partículas totais em suspensão) e PM10 (fração de partículas atmosféricas com diâmetro aerodinâmico menor que $10 \mu \mathrm{m}$, fração inalável por humanos) do MPA em dois pontos distintos: (i) Porto de Aratu, impactado pelo intenso movimento de manufaturados tais como minerais, coque e outros concentrados e próximo ao Centro Industrial de Aratu e do Polo Petroquímico de Camaçari, e (ii) Bananeira, comunidade de pescadores localizada na Ilha de Maré. Na figura 2 é apresentada uma comparação do aspecto geral de um filtro utilizado para coleta de partículas na fração PM10, provenientes do Porto de Aratu, no início e no término de um período de $24 \mathrm{~h}$ de amostragem.

A concentração gravimétrica da fração PTS variou de 36,1 $\mathrm{g} \mathrm{m}^{-3}$ (Bananeira) a 175 $\mu \mathrm{g} \mathrm{m}^{-3}$ (Aratu) enquanto de PM10 foi de 112 $\mu \mathrm{g} \mathrm{m}^{-3}$ para o Porto de Aratu (Tabela 1). Os valores encontrados para esses sítios estudados, exceto para Bananeira, são superiores aos valores permitidos pelos padrões brasileiros. Os níveis atmosféricos de $\mathrm{Cu}, \mathrm{Fe}, \mathrm{Mn}$ e $\mathrm{Zn}$ encontrados no material particulado desses sítios de estudo são apresentados na Tabela 1.

O Fe foi o elemento mais abundante no Porto de Aratu (277 $\mathrm{ng} \mathrm{m}^{-3}$ para PTS e $142 \mathrm{ng}$ $\mathrm{m}^{-3}$ para $\mathrm{PM} 10$ ) enquanto que para Bananeira o elemento mais abundante foi Zn (145 ng m ${ }^{3}$ ) na fração PTS. As principais fontes para Fe e $\mathrm{Cu}$ no Porto de Aratu foram descargas de concentrados de $\mathrm{Cu}$, fertilizantes e minérios nos terminais, embora sejam possíveis que outras fontes, tais como a queima de diesel nos barcos, tenham também contribuído significantemente para o aumento dos níveis atmosféricos destes elementos. Por sua vez, os metais encontrados em Bananeira demonstraram comportamentos distintos, visto que $\mathrm{Zn}$ foi o elemento mais abundante, apresentando fonte antrópica específica para esse local como, por exemplo, o Centro Industrial de Aratu e/ou uma planta siderúrgica localizada no seu entorno.

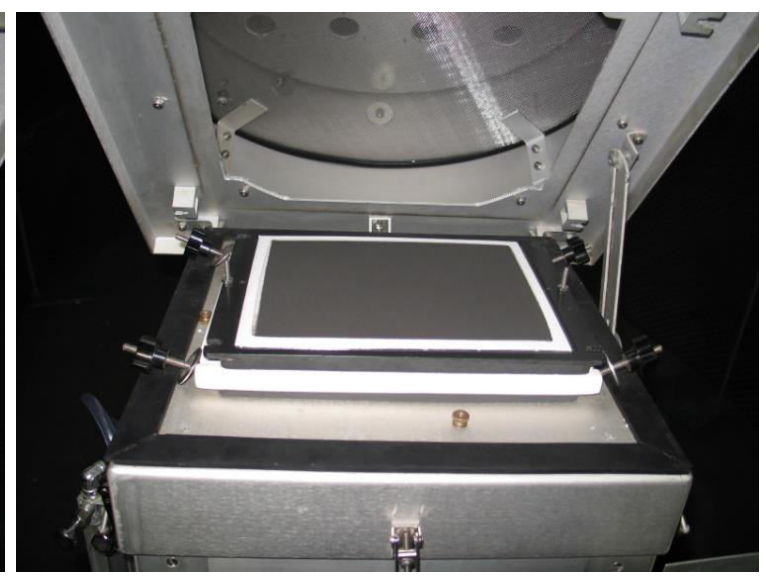

(b)

Figura 2. Amostra de PM10 coletada durante $24 \mathrm{~h}$ no Porto de Aratu. Em (a) aspecto do filtro antes de iniciar a coleta do material particulado atmosférico e em (b) o mesmo filtro após $24 \mathrm{~h}$ de exposição às partículas atmosféricas 
Em Aratu, os fatores de enriquecimento (FE) para cobre, baseados na ocorrência natural de $\mathrm{Fe}$, esteve entre 166 e 644. As altas concentrações de $\mathrm{Cu}$ devem estar principalmente relacionadas às atividades portuárias. Além disso, outras fontes possíveis poderiam ser a queima de diesel e de óleo pesado utilizados nas embarcações. ${ }^{14}$ Como já comentado, material particulado total coletado em Bananeira apresentou perfil diferente, sendo o $\mathrm{Zn}$ o elemento mais abundante $\left(0,2\right.$ a $\left.243 \mathrm{ng} \mathrm{m}^{-3}\right)$. Ainda referindo-se à Bananeira, o FE encontrado para Zn foi elevado (3630), evidenciando fortes contribuições antrópicas, seguido pelo $\mathrm{Cu}$ (192) e $\mathrm{Mn}$ (45). Até o presente conhecimento, Bananeira não tem fontes locais significativas de nenhum dos metais estudados e ainda o Porto de Aratu não possui fontes de $\mathrm{Zn}$ significativamente contribuidoras para os níveis encontrados em Bananeira. Desse modo, Bananeira é considerada um sítio receptor de MPA de outras regiões.

Macedo et $a l^{12}$ realizaram um estudo de especiação de arsênio inorgânico [As total, As (III) e As (V)] com algumas amostras de PTS de Bananeira. Nessas amostras a concentração de As total variou de 3,8 a 20 $\mathrm{ng} \mathrm{m}^{-3}$ enquanto as concentrações de As (III) variaram de 2,7 a $10,5 \mathrm{ng} \mathrm{m}^{-3}$. De posse dos valores de concentração de As total e As (III), foram obtidas as concentrações de As (V) que variaram de 1,1 a 9,5 $\mathrm{ng} \mathrm{m}^{-3}$. De maneira similar, Ferreira et $a l^{17}$ realizaram também estudo de especiação de $\mathrm{Sb}$ inorgânico [Sb total, Sb (III) e Sb (V)] no mesmo lote de amostras (Bananeira PTS). As concentrações de $\mathrm{Sb}$ total variaram de 4,32 a 4,60 $\mathrm{ng} \mathrm{m}^{-3} \mathrm{e}$ as concentrações de $\mathrm{Sb}$ (III) variaram de 0,33 a $0,67 \mathrm{ng} \mathrm{m}^{-3}$. De modo similar ao comentado acima, os valores calculados das concentrações de $\mathrm{Sb}(\mathrm{V})$ variaram de 3,93 a $3,99 \mathrm{ng} \mathrm{m}^{-3}$. Entretanto, é necessário ressaltar que os níveis atmosféricos de As e $\mathrm{Sb}$ reportados nos estudos de Macedo et $\mathrm{al}^{20}$ e Ferreira et $\mathrm{al}^{25}$ referem-se a um número muito pequeno de amostras e, portanto, não podem ser considerados como representativos da região amostrada. Considerando-se que há poucos estudos na literatura que consideram a especiação de elementos traço no MPA, novos estudos que vierem a ser desenvolvidos na BTS poderão servir de base para melhor compreender o papel destas espécies no MP e servir de referencial para outras regiões costeiras tropicais ao redor do mundo.

Estimativas de fluxo de deposição seca $\left(F_{d}\right)\left(\mu \mathrm{g} \mathrm{m}^{-2} \mathrm{dia}^{-1}\right)$ de $\mathrm{Cu}, \mathrm{Fe}, \mathrm{Mn}$ e $\mathrm{Zn}$ do material particulado atmosférico foram feitos e estão apresentados na figura 3. Os níveis de $F_{d}$ foram altos, principalmente para $\mathrm{Fe}$ seguido pelo $\mathrm{Mn}$ para todos os sítios investigados. Ainda, o Zn também apresentou valor de $F_{d}$ importante para Bananeira, já que havia se apresentado com níveis atmosféricos mais elevados principalmente para esse sítio. Embora mais estudos ainda precisem ser realizados para melhor compreensão, a deposição seca apresenta-se como um mecanismo de remoção atmosférica importante para esses elementos no entorno da BTS. ${ }^{14}$

No que se refere aos níveis atmosféricos apresentados por metais ( $\mathrm{Cu}, \mathrm{Fe}, \mathrm{Mn}$ e $\mathrm{Zn}$ ) no MPA, se comparados com as concentrações encontradas de outras regiões costeiras no Brasil $^{18,19}$ e de outros lugares do mundo, ${ }^{20-23}$ os sítios estudados na BTS apresentam valores inferiores. Logo, isso sugere que a BTS não se apresenta contaminada por metais no MPA. Entretanto, mais estudos ainda devem ser realizados considerando um número maior de sítios de amostragem por um período de tempo mais longo, para fazer uma melhor avaliação de metais no MPA da BTS. 
Tabela 1. Níveis atmosféricos $\left(\mathrm{ng} \mathrm{m}^{-3}\right)$ de metais associados às partículas do entorno da BTS e outras localidades

\begin{tabular}{|c|c|c|c|c|c|}
\hline Locais (fração de tamanho) & $\begin{array}{c}\mathrm{Cu} \\
\left(\mathrm{ng} \mathrm{m}^{-3}\right)\end{array}$ & $\begin{array}{c}\mathrm{Fe} \\
\left(\mathrm{ng} \mathrm{m}^{-3}\right)\end{array}$ & $\begin{array}{c}\mathrm{Mn} \\
\left(\mathrm{ng} \mathrm{m}^{-3}\right)\end{array}$ & $\begin{array}{c}\mathrm{Zn} \\
\left(\mathrm{ng} \mathrm{m^{-3 }}\right)\end{array}$ & $\begin{array}{c}\text { PM } \\
\left(\mu \mathrm{g} \mathrm{m}^{-3}\right)\end{array}$ \\
\hline Porto de Aratu, BTS (PTS) ${ }^{14}$ & 71,2 & 277 & 16,3 & 4,24 & 175 \\
\hline Porto de Aratu, BTS $\left(\mathrm{PM}_{10}\right)^{14}$ & 44,0 & 142 & 8,92 & 2,32 & 68,2 \\
\hline Bananeira, BTS (PTS) ${ }^{14}$ & 3,37 & 26,8 & 19,5 & 145 & 36,1 \\
\hline Rio de Janeiro, RJ $(\mathrm{PM} 10)^{18}$ & 22 & 775 & 16 & 2124 & - \\
\hline Barra Mansa, RJ (PM10) ${ }^{19}$ & 65 & 1668 & 88 & 488 & - \\
\hline Espanha, região costeira (PM10) & 4,8 & - & 41,1 & - & 14 \\
\hline Coreia, região costeira e industrial (PM10) ${ }^{21}$ & - & 958 & 16 & 544 & - \\
\hline China, região costeira $(\mathrm{PM} 10)^{22}$ & 0,06 & 4483 & 404 & 0,95 & 274 \\
\hline Edinburgh, UK, região costeira $(\mathrm{PM} 10)^{23}$ & 4,9 & 183 & 2,9 & 13,3 & 14,2 \\
\hline
\end{tabular}

As referências utilizadas para compor essa tabela são: Pereira et al. ${ }^{14}$ Toledo et al. ${ }^{18}$ Loyola et al. ${ }^{19}$ Arruti et al. $;^{20}$ Park e Dam; ${ }^{21}$ Kong et al. ${ }^{22}$ e Heal et al. ${ }^{23}$

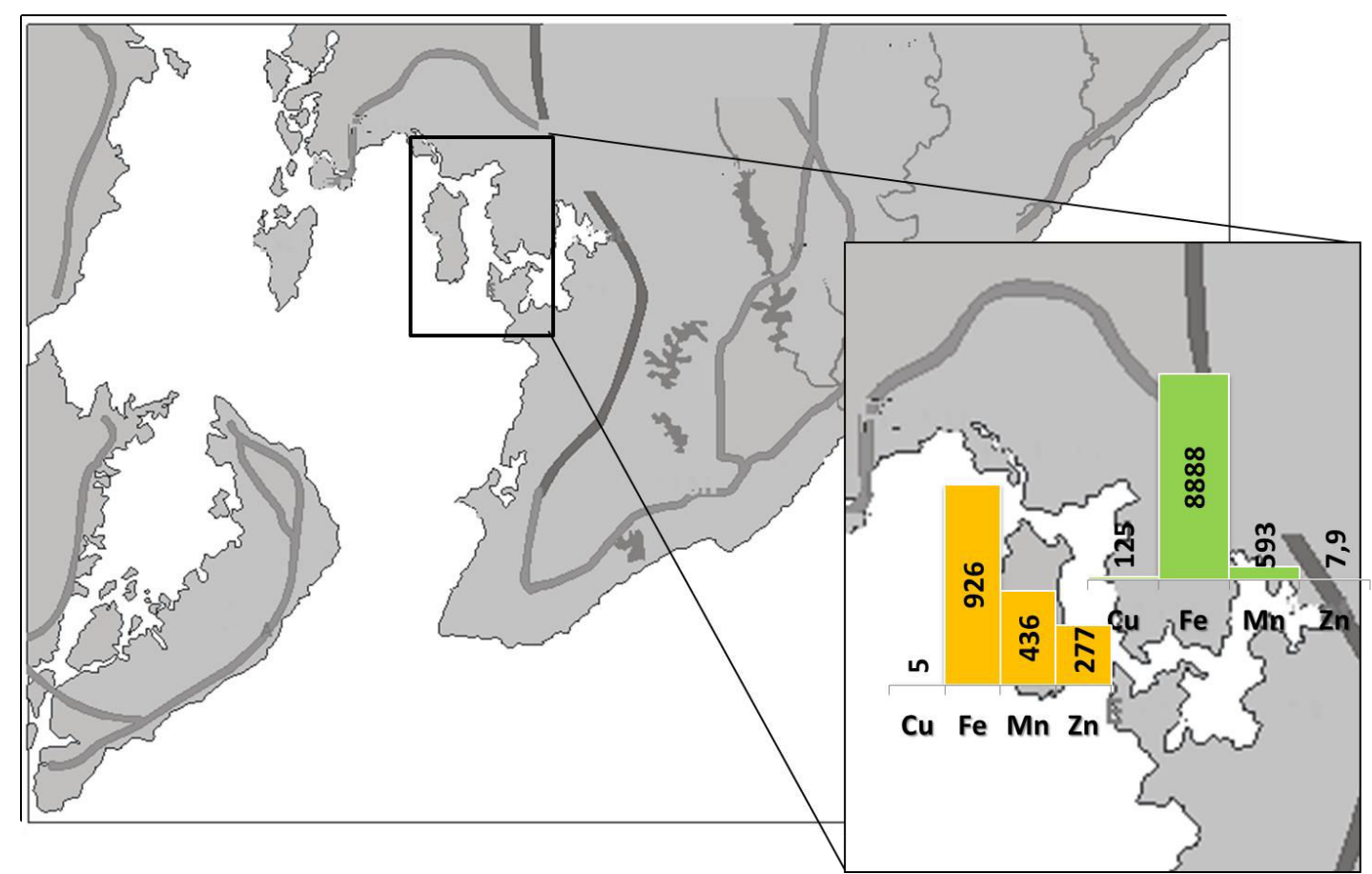

Figura 3. Estimativas de fluxo de deposição seca $\left(F_{d}\right)\left(e m \mu g \mathrm{~m}^{-2}\right.$ dia $\left.{ }^{-1}\right)$ para os metais investigados no material particulado atmosférico de algumas localizações da BTS. Em amarelo estão representados os $F_{d}$ da fração PTS de Bananeira e em verde estão representados os $F_{d}$ fração PTS do Porto de Aratu. Dados modificados de Pereira et al. ${ }^{14}$

\section{Hidrocarbonetos Policíclicos Aromáticos (HPA)}

No trabalho de da Rocha et al ${ }^{13}$ foram estudados os níveis de 16 hidrocarbonetos policíclicos aromáticos (HPA), considerados prioritários pela EPA, associados ao MPA provenientes da BTS. Os HPA estudados foram: naftaleno (NAP), acenafteno (ACE), acenaftileno (ACY), fluoreno (FLUO), 
fenantreno (PHE), antraceno (ANT) fluoranteno (FLT), pireno benzo[a]antraceno $(\mathrm{BaA})$, criseno benzo[b]fluoranteno benzo[k]fluoranteno (BkF), benzo[a]pireno (BaP), dibenz[ah]antraceno (DBA) e benzo[ghi]perileno (BgP).

Na Tabela 2 é possível observar comparação dos níveis de HPA nas frações TSP e PM10 para os mesmos sítios (Porto de Aratu e Bananeira) e também para Itaparica, com os valores encontrados em outras regiões costeiras do Brasil e do mundo. Os resultados encontrados para o entorno da BTS mostraram que o $\operatorname{BbF}(0,130-6,85 \mathrm{ng} m$ $\left.{ }^{3}\right)$ foi o HPA com as concentrações mais elevadas em Aratu e Bananeira; e este mesmo HPA também apresentou-se majoritariamente para Itaparica $(0,040-1,22$ ng $\left.\mathrm{m}^{-3}\right)$. As fontes de HPA nos sítios estudados foram principalmente de origem antrópica, tais como veículos de pequeno e grande porte, carregamentos do porto, ressuspensão de partículas do solo, queima de diesel das embarcações e a queima de carvão e madeira para produção de energia. $\mathrm{Na}$ Figura 4 estão apresentadas as concentrações atmosféricas dos HPA mais pesados bem como as comparações dos níveis de HPA entre os sítios estudados. Entretanto, foram encontrados níveis atmosféricos de HPA mais elevados para Cubatão (Estuário de Santos) e outros locais do mundo.
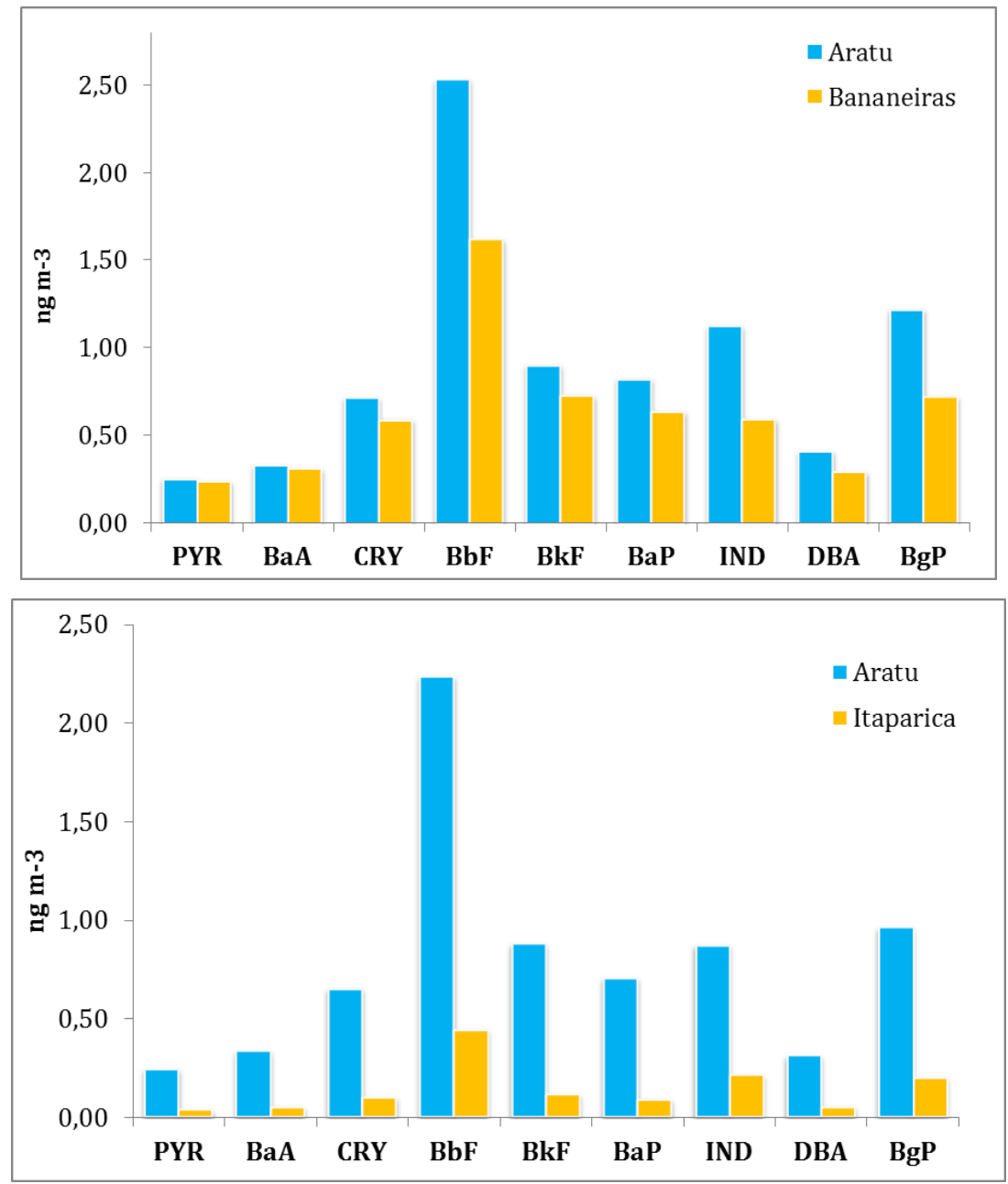

Figura 4. Níveis atmosféricos de HPA encontrados em diferentes localidades no entorno da BTS. Em (a) fração PTS e (b) fração PM10. Adaptado de da Rocha et al. ${ }^{13}$ e Guarieiro et al. ${ }^{25}$ 
Os HPA representaram entre $0,005 \%$ e $0,0012 \%$ da massa de PTS para o Porto de Aratu e Bananeira, respectivamente. Ainda, os mesmos representaram $0,008 \%$ da massa de PM10 para Porto de Aratu. O conteúdo de HPA na fase particulada (em $\mu \mathrm{g} \mathrm{g}^{-1}$ ) foi de 48,9; 76,5 e 119 para Aratu PTS, Aratu PM10 e Bananeira, respectivamente. Na figura 5 é possível observar as contribuições relativas entre HPA carcinogênicos ( $\mathrm{BaA}, \mathrm{BbF}, \mathrm{BkF}$, $B a P, D B A$ e IND) e não-carcinogênicos entre os diferentes sítios. Nos três sítios amostrados, a contribuição relativa dos HPA carcinogênicos foi similar (cerca de 70 \%) enquanto que a contribuição relativa dos HPA carcinogênicos de Cubatão (Estuário de Santos, SP - região costeira altamente industrializada) é apenas de $59 \% .{ }^{24}$ Esse fato interessante do ponto de vista ambiental, pode evidenciar sérias preocupações no que se refere ao efeito a saúde, principalmente das comunidades ribeirinhas.
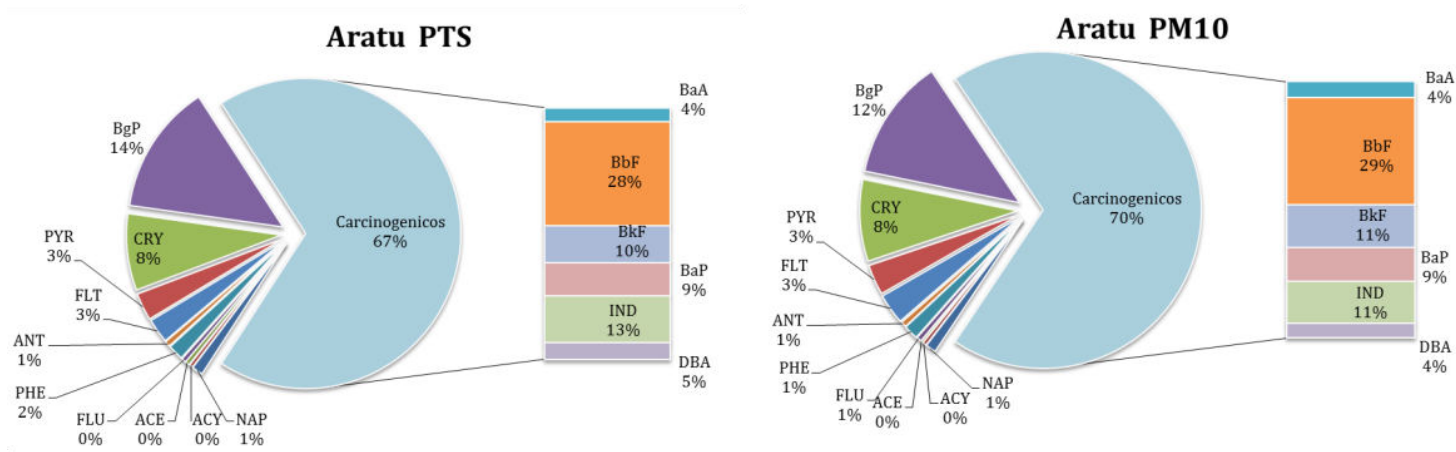

Bananeira PTS

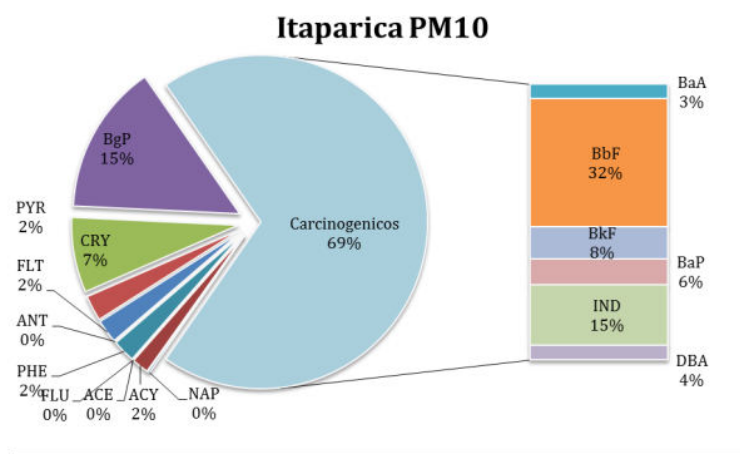

Figura 5. Contribuições percentuais individuais dos HPA e espécies carcinogênicas presentes no material particulado atmosférico para os sítios estudados na BTS ${ }^{13}$

O fluxo de deposição seca $\left(F_{d}\right)$ do total de HPA mais elevado foi encontrado para o Porto de Aratu PTS $\left(3,33 \mu \mathrm{g} \mathrm{m}^{-2} \mathrm{dia}^{-1}\right)$ seguido por Bananeira PTS $\left(2,49 \mu \mathrm{g} \mathrm{m}^{-2} \mathrm{dia}^{-1}\right)$, Aratu PM10 $\left(2,44 \mu \mathrm{g} \mathrm{m}^{-2} \text { dia }^{-1}\right)^{13}$ e Itaparica PM10. ${ }^{25}$ $\mathrm{Na}$ figura 6 é possível observar as contribuições dos HPA carcinogênicos, dos HPA não-carcinogênicos e os teores para o fluxo de deposição seca de HPA total das localidades consideradas nos estudos da BTS. $^{13,25}$

Fontes de HPA nos sítios estudados foram principalmente de origem antrópica. Para Aratu (PTS e PM10) as principais fontes de HPA foram emissão veicular (carros movidos à gasolina e a diesel), descargas no porto (coque e outros) e poeira doméstica. Bananeira, apesar de ser um local remoto, teve como contribuições as seguintes fontes: queima de diesel a partir de navios e embarcações menores, fuligem doméstica, queima de carvão e de madeira para produção de energia. ${ }^{13}$

Apesar do MPA de Itaparica apresentar-se 
enriquecido em relação aos HPA (que são provenientes de fontes antrópicas), os níveis de concentrações individuais de HPA e $\Sigma$ HPA no MPA deste sítio são iguais ou inferiores aos níveis de outras regiões costeiras, como em Cubatão, ${ }^{24}$ Rio de Janeiro, ${ }^{27}$ background urbano de São Paulo, ${ }^{28}$ Ásiaa $^{29}$ e Atenas. ${ }^{30}$ Entretanto, Bananeira e Porto de Aratu apresentaram $\Sigma$ HPA superior a alguns desses locais citados mas inferior a Cubatão.
Provavelmente, os níveis de HPA encontrados nessa região (Bananeira e Aratu) devem ser provenientes de atividade industrial, tais como Polo Petroquímico de Camaçari e Centro Industrial de Aratu, além das atividades portuárias. Logo, muito provavelmente a atmosfera da BTS apresenta contaminação leve (região de Itaparica) a moderada (Bananeira e Porto de Aratu) em relação aos HPA estudados.

Tabela 2. Níveis atmosféricos $\left(\mathrm{ng} \mathrm{m}^{-3}\right)$ de HPA associados às partículas do entorno da BTS e outras localidades

\begin{tabular}{|c|c|c|c|c|c|c|c|c|c|c|}
\hline Locai & PYR & BaA & CRY & $3 \mathrm{bF}$ & $\mathrm{kF}$ & $\mathrm{BaP}$ & IND & DBA & BgP & $\Sigma \mathrm{HPA}$ \\
\hline Porto de Aratu, B & 0,26 & 0,33 & 0,72 & 2,53 & 0,90 & 0,82 & 1,12 & 0,41 & 1,22 & 8,95 \\
\hline Porto de Aratu, BTS (PM10) & 0,17 & 0,23 & 0,45 & 1,53 & 0,59 & 0,49 & 0,65 & 0,23 & 0,72 & 7,75 \\
\hline Bananeira, BTS (PTS) ${ }^{13}$ & 0,24 & 0,32 & 0,59 & 1,62 & 0,73 & 0,64 & 0,59 & 0,29 & 0,72 & 6,24 \\
\hline Itaparic & 0,03 & 0,05 & 0,10 & 0,44 & 0,11 & 0 & 21 & 0,05 & 0,20 & 1,36 \\
\hline $\begin{array}{r}\text { Cubatão, Estuá } \\
\text { (PM1 }\end{array}$ & & & & 282 & 97 & & & ,85 & 2,32 & 16,7 \\
\hline $\begin{array}{r}\text { Niterói, Baía d } \\
\text { (TSP }\end{array}$ & & & & & 0,06 & 0,06 & & & & 0,62 \\
\hline $\begin{array}{r}\text { Rio de Janei } \\
\text { (PM1 }\end{array}$ & & & & & & & & & &,$<0$ \\
\hline $\begin{array}{l}\text { São Paulo (bac } \\
\text { urbano) (PI }\end{array}$ & & & & & & & & 0,062 & & $2,<0$ \\
\hline $\begin{array}{l}\text { ste da Ásia, próximo à cost } \\
(\text { (PM10) }\end{array}$ & & 0,079 & 0,136 & 0,144 & 0,063 & 0,147 & 0,187 & 0,016 & 0,101 & 1,2 \\
\hline Atenas, Grécia (PM10) ${ }^{30}$ & 18 & 0,23 & 0,40 & 0,67 & & 0,23 & 0,32 & 0,06 & 0,36 & 2,78 \\
\hline
\end{tabular}

As referências utilizadas para compor essa tabela são: da Rocha et al. ${ }^{14}$ Allen et al..; ${ }^{24}$ Guarieiro et al. ${ }^{25}$ Lima e Pereira Neto; ${ }^{26}$ Azevedo et al. ${ }^{27}$ Vasconcellos et al. ${ }^{28}$ Ding et al. ${ }^{29} e$ Vasilakos et al..$^{30}$ 


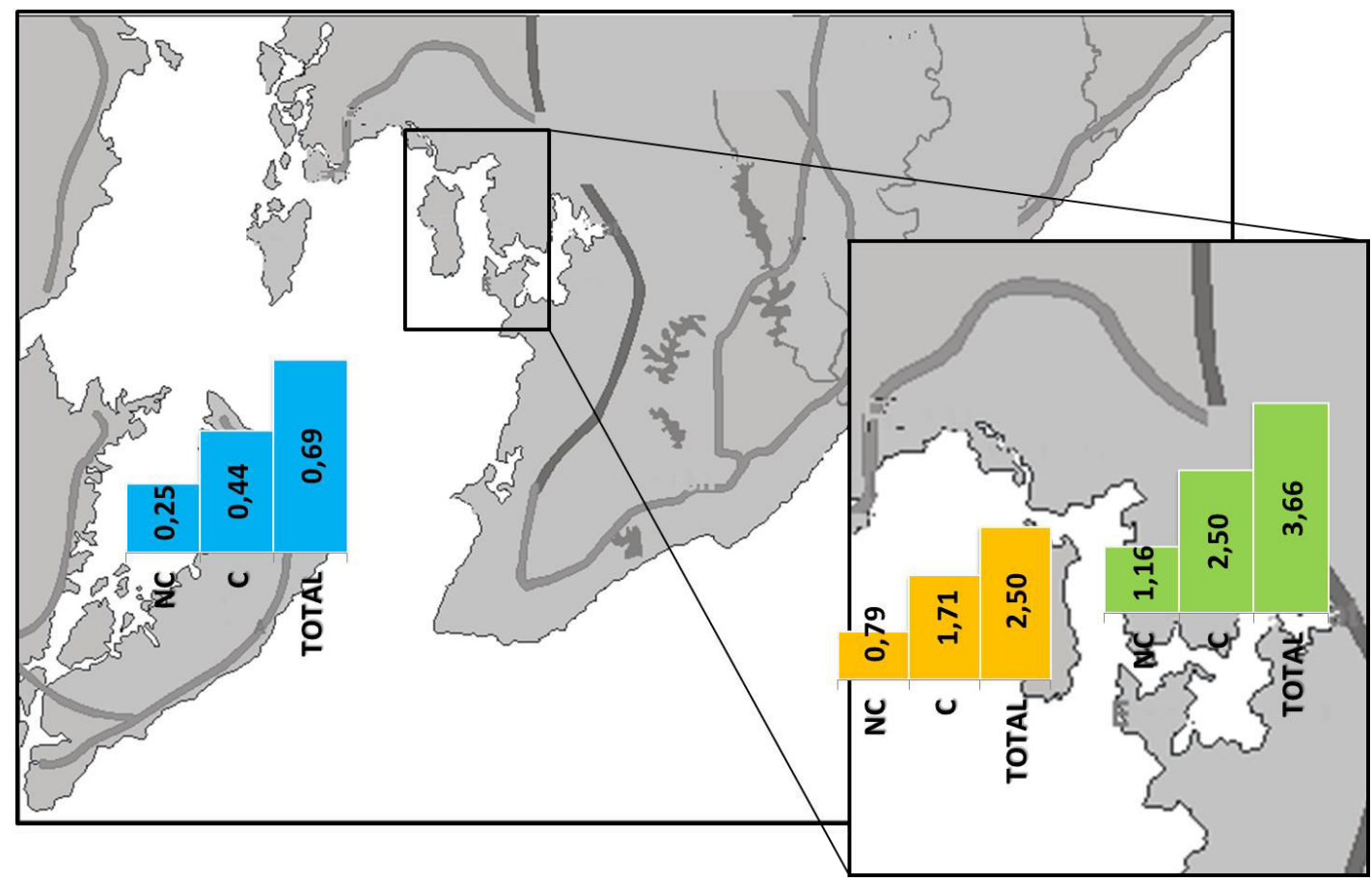

Figura 6. Estimativas de fluxo de deposição seca $\left(F_{d}\right)\left(e m \mu g m^{-2}\right.$ dia $\left.^{-1}\right)$ para os HPA investigados no material particulado atmosférico de algumas localizações da BTS. Os termos " $N C$ " significa HPA não carcinogênicos, " $C$ " significa HPA carcinogênicos e "TOTAL" significa concentração total de HPA. Em amarelo estão representados os $F_{d}$ da fração PTS de Bananeira, em verde estão representados os $F_{d}$ fração PTS do Porto de Aratu e em azul estão representados os $\mathrm{F}_{\mathrm{d}}$ da fração PM10 de Itaparica. Modificado de da Rocha et al. ${ }^{13}$ e de Guarieiro et al. ${ }^{25}$

\section{Principais contaminantes da hidrosfera}

O desenvolvimento industrial, o precário e/ou ausente sistema de tratamento de esgotos e a alta taxa de urbanização no entorno da Baía tem causado a degradação da qualidade dos diversos ecossistemas presentes na BTS (recifes de corais, estuários, mangues, ilhas, etc.). A seguir serão apresentados os cenários de contaminação dos sedimentos, material particulado em suspensão, algas e biota por metais e hidrocarbonetos na BTS.

\subsection{Material particulado em suspensão e em sedimentos}

\section{Metais traço e ametais}

O material particulado em suspensão (MPS) presente na água dos rios pode ser uma importante via de transporte de contaminantes do continente para a zona costeira. Mais de $50 \%$ do $\mathrm{Pb}, \mathrm{Zn}, \mathrm{Cr}, \mathrm{Co}, \mathrm{Cu}$ são transportados como MPS, mesmo quando as concentrações do material particulado são baixas nas águas, como é o caso dos rios que desembocam na BTS (2 - 86 $\mathrm{mg} \mathrm{kg})^{-1} .^{5}$

Nos estuários, as concentrações dos metais são, de modo geral, mais altas à montante dos rios e diminuem em direção à foz. Porém, como os ambientes estuarinos são altamente dinâmicos, existem vários exemplos de desvio deste tipo de comportamento. ${ }^{5,31,32}$ Uma série de variáveis como a salinidade, concentração de material 
particulado em suspensão, $\mathrm{pH}$, fontes antrópicas, entre outros, controlam as concentrações e padrões de distribuição observados nos estuários. Na Figura 7 é possível observar medições in situ de alguns desses parâmetros durante a coleta de amostras. A Tabela 3 mostra as concentrações de metais traço associados ao material particulado em suspensão nos principais estuários da região.

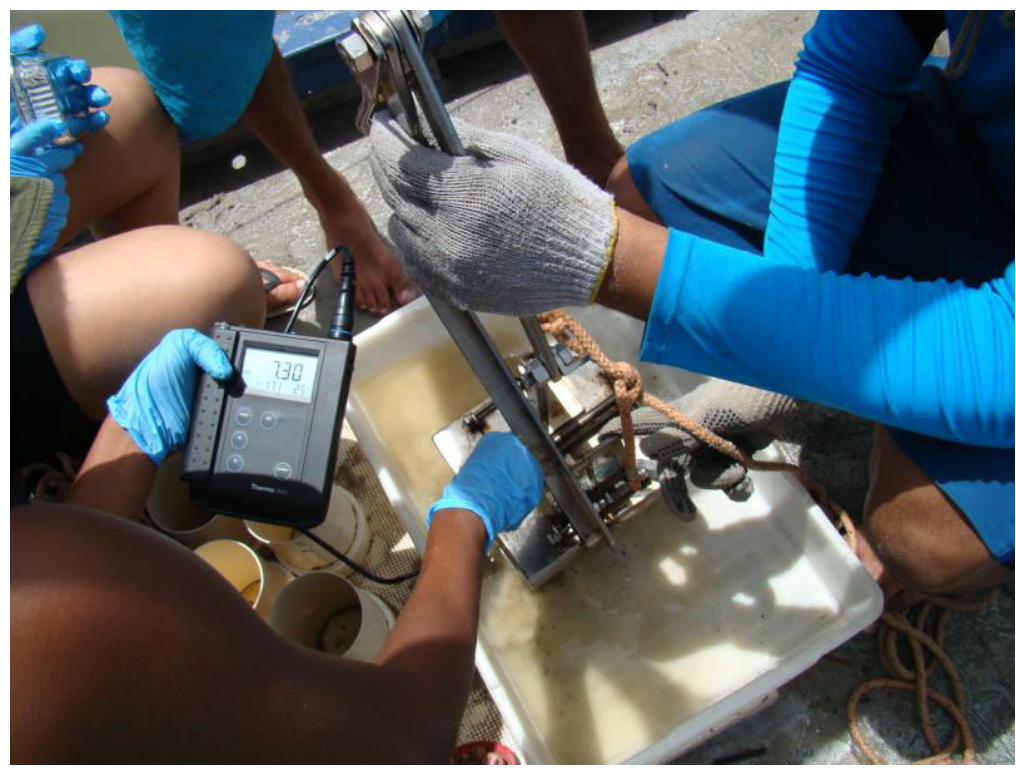

Figura 7. Medições in situ de alguns parâmetros físico-químicos ( $\mathrm{pH}$, salinidade, etc.) durante uma coleta de amostras no Rio Subaé, BTS

O $\mathrm{Mn}$, seguido por $\mathrm{Zn}$ e $\mathrm{Pb}$ são os elementos que apresentaram os maiores fluxos para a Baía. ${ }^{33,34}$ Hatje et al. ${ }^{33}$ mostraram que, dentre os principais tributários, o rio Subaé é a principal fonte de material particulado em suspensão e de metais traço para a BTS. Dados apresentados pelo CRA $^{35}$ indicaram que os rios Dom João e Mataripe, localizados nas proximidades da refinaria Landulfo Alves (RLAM), são fontes importantes de $\mathrm{Hg}$, enquanto os rios Dom João, Mataripe e São Paulo, representam fontes de As para a BTS.

Análise química de metais feita em sedimentos dos estuários dos rios Subaé, Paraguaçu e Jaguaripe, mostrou que os sedimentos do Subaé são mais enriquecidos com $\mathrm{Cd}, \mathrm{Pb}$ e $\mathrm{Zn}$, do que os sedimentos dos outros dois estuários. ${ }^{5,35-37}$ A contaminação por Pb na BTS foi previamente relatada na literatura (Tabela 5)..$^{38-46}$ As áreas mais críticas foram observadas no rio Subaé, na Baía de Itapagipe e no Porto de Aratu. As atividades industriais, o $\mathrm{CIA}$ e o transporte marítimo, também contribuem com aportes de $\mathrm{Pb}$ para a Baía de Itapagipe. A figura 8 mostra a coleta de sedimentos submersos por águas da BTS e em regiões de mangue.

No Subaé, os sedimentos do rio foram contaminados por $\mathrm{Pb}, \mathrm{Cd}$, As e $\mathrm{Zn}$ lançados pela antiga Plumbum/COBRAC, que funcionou à $300 \mathrm{~m}$ do rio Subaé, no período de 1960 a 1993, no município de Santo Amaro. Zinco e Cd eram metais presentes no minério de $\mathrm{Pb}$ utilizado pela Plumbum. $\mathrm{Na}$ década de 1970, um estudo pioneiro sobre a contaminação por metais no Subaé mostrou que as concentrações de $\mathrm{Cd}$ e $\mathrm{Pb}$ nas águas deste rio excediam de 8 a 16 vezes os limites estabelecidos pela Organização Mundial da Saúde. Mais de 30 anos depois deste primeiro estudo, os teores de $\mathrm{Pb}$ em águas subterrâneas coletadas no município de Santo Amaro, nas proximidades da Plumbum, ainda são bastante elevados atingindo valores superiores a $230 \mu \mathrm{g} \mathrm{L}^{-1}$, muito acima 
do limite preconizado na legislação brasileira, Portaria 518/04 do Ministério da Saúde. Mesmo desativada, os resíduos da Plumbum continuam sendo uma fonte significativa de $\mathrm{Pb}, \mathrm{Zn}$ e $\mathrm{Cd}$, contaminando o lençol freático, o material particulado em suspensão e sedimento do rio Subaé. A contaminação severa causou ainda efeitos negativos em organismos (macrofauna bêntica) presentes nos sedimentos do rio Subaé e para a saúde da população local. ${ }^{42-45}$

Tabela 3. Teores de metais traço $\left(\mu \mathrm{g} \mathrm{g}^{-1}\right)$ associados ao material particulado nos estuários da BTS, BA

\begin{tabular}{ccccccc}
\hline \multirow{2}{*}{ Elemento } & \multicolumn{2}{c}{ Paraguaçu } & \multicolumn{2}{c}{ Subaé } & \multicolumn{2}{c}{ Jaguaripe } \\
\cline { 2 - 7 } & mínimo & máximo & mínimo & máximo & mínimo & máximo \\
\hline $\mathrm{Cd}$ & $>0,001$ & 0,61 & $>0,001$ & 3,47 & $>0,001$ & $>0,001$ \\
$\mathrm{Co}$ & 0,89 & 13,3 & 9,15 & 48 & 2,24 & 12,9 \\
$\mathrm{Cr}$ & 1,98 & 10,2 & 1,4 & 13,6 & 2,69 & 19,4 \\
$\mathrm{Cu}$ & 3,11 & 11,6 & 12,3 & 38,9 & 2,67 & 14,1 \\
$\mathrm{Ni}$ & 8,59 & 33,4 & 9,94 & 22,3 & 2,42 & 13 \\
$\mathrm{Mn}$ & 480 & 4130 & 482 & 6027 & 1581 & 2883 \\
$\mathrm{~Pb}$ & 5 & 19,9 & 30,7 & 125 & 5,77 & 22,3 \\
$\mathrm{Zn}$ & 9,35 & 46,6 & 62,7 & 212 & 14,4 & 64,4 \\
\hline
\end{tabular}

Modificado de Hatje et al. ${ }^{5}$

Os maiores enriquecimentos por Zn são encontrados nos sedimentos do rio Subaé e da Baía de Itapagipe ${ }^{35}$. Na Baía de Itapagipe, os sedimentos também são contaminados por $\mathrm{Hg}$, devido à atuação da Companhia Química do Recôncavo, que operou durante 12 anos, às margens da baía, produzindo cloro e soda cáustica ${ }^{46}$ e descarregando 900 $\mathrm{kg}$ ano ${ }^{-1}$ de $\mathrm{Hg}$ no ambiente. ${ }^{47}$ Nas áreas das Baías de Itapagipe e Aratu, bem como em alguns pontos de Mataripe, as indústrias de produtos químicos orgânicos e metálicos, as atividades petrolíferas e os esgotos domésticos contribuem para os elevados teores de $\mathrm{Cd}^{5}$

Elevados teores de $\mathrm{Cu}$ foram observados em várias regiões da BTS, refletindo a importância das fontes antrópicas deste elemento distribuídas ao redor de toda a baía. ${ }^{33,38,41,42}$ As principais fontes de Cu são os efluentes domésticos, as indústrias de refino de petróleo, de produtos químicos orgânicos e inorgânicos e de metais primários, localizadas na Baía de Aratu, indústrias de acabamento de produtos metálicos e, principalmente, portos e terminais onde o minério de cobre é transportado. Um lixão/aterro em Itapagipe, em operação até a década de 1970, também contribuiu com o aporte de $\mathrm{Cu}, \mathrm{Zn}$ e outros elementos. ${ }^{35}$

Os maiores enriquecimentos de $\mathrm{Mn}$ foram observados nas Baías de Aratu e Iguape e na desembocadura do rio Subaé..$^{33,35,38}$ Cabe esclarecer, que os teores naturais deste elemento, para a região, são relativamente altos e, portanto, devem ser considerados quando da avaliação da contaminação por Mn na BTS.

Concentrações altas de As foram encontradas em toda a BTS, principalmente na foz do rio Subaé, no Porto de Aratu e em Itapagipe. As atividades de refino de petróleo, atividades industriais e o tráfego naval na baía e Porto de Aratu, são fontes de As. ${ }^{35}$ Os defensivos agrícolas, as rações utilizadas na carcinicultura e os produtos químicos utilizados para proteger embarcações de madeira, muito utilizadas na BTS, são também fontes potenciais de As. Concentrações elevadas de As no rio Jaguaripe são, potencialmente, de origem natural, visto que a bacia de drenagem é relativamente bem preservada e apresenta pouca atividade antrópica. ${ }^{48}$ 
Tabela 4. Concentração mínima e máxima de metais e ametais ( $\mu \mathrm{g} \mathrm{g}^{-1}$, peso seco) em sedimentos da BTS e de outros estuários e baías

\begin{tabular}{|c|c|c|c|c|c|c|c|c|c|c|}
\hline \multirow{2}{*}{ Local } & \multicolumn{2}{|c|}{$\mathrm{Zn}\left(\mu \mathrm{g} \mathrm{g}^{-1}\right)$} & \multicolumn{2}{|c|}{$\mathrm{Pb}\left(\mu \mathrm{g} \mathrm{g}^{-1}\right)$} & \multicolumn{2}{|c|}{$\mathrm{Cu}\left(\mu \mathrm{g} \mathrm{g}^{-1}\right)$} & \multicolumn{2}{|c|}{$C d\left(\mu g^{-1}\right)$} & \multicolumn{2}{|c|}{ As $\left(\mu g^{-1}\right)$} \\
\hline & Mín. & Máx. & Mín. & Máx. & Mín. & Máx. & Mín. & Máx. & Mín. & Máx. \\
\hline Baía de Todos os Santos ${ }^{46}$ & 4,00 & 1646 & 2,00 & 780 & 3,00 & 666 & 0,650 & 3,00 & - & - \\
\hline Baía de Todos os Santos ${ }^{39}$ & 2,20 & 774 & 2,00 & 359 & 1,90 & 404 & - & - & - & - \\
\hline Baía de Todos os Santos ${ }^{35}$ & 0,44 & 332 & 0,16 & 107 & 0,16 & 429 & 0,003 & 5,56 & 0,012 & 71,9 \\
\hline Baía de Todos os Santos ${ }^{33}$ & 37,2 & 667 & 10,9 & 325 & 10,4 & 21,8 & 0,20 & 3,48 & - & - \\
\hline Baía de Todos os Santos ${ }^{37}$ & 20,1 & 32,5 & 10,7 & 34,5 & 4,25 & 15,2 & $<\mathrm{LD}$ & 0,21 & - & - \\
\hline Baía de Guanabara ${ }^{49}$ & 266 & 825 & 101 & 198 & 100 & 300 & $<0,01$ & $<0,01$ & - & - \\
\hline Baía de Guanabara ${ }^{50}$ & 5 & 755149 & 2 & 19340 & 2 & 18840 & - & - & - & - \\
\hline $\begin{array}{l}\text { Porto de Niterói, Baía de } \\
\text { Guanabara }\end{array}$ & 115 & 850 & 45 & 120 & 35 & 1450 & - & - & - & - \\
\hline Baía de Sepetiba ${ }^{52}$ & 54 & 779 & 20 & 55 & 0,89 & 42,5 & 0,34 & 4,90 & - & - \\
\hline Estuário de Santos ${ }^{53}$ & 53 & 476 & 9 & 127 & 13 & 109 & $<\mathrm{LD}$ & 1,6 & - & - \\
\hline Estuário de Santos ${ }^{54}$ & 20,4 & 231 & 1,08 & 37,8 & 2,88 & 38,4 & 0,04 & 0,34 & - & - \\
\hline Porto de Santos ${ }^{55}$ & 509 & 1077 & 3,97 & 16,7 & 6,98 & 27,3 & $<0,60$ & $<0,60$ & - & - \\
\hline
\end{tabular}

As referências utilizadas para compor essa tabela foram: Hatje et al.; ${ }^{33}$ CRA 2004; ${ }^{35}$ Barros et al.; ${ }^{37}$ CRA 1997; ${ }^{39}$ CRA 1996; ${ }^{46}$ Barbosa et al.; ${ }^{49}$ Batista Neto et al.; ${ }^{50}$ Batista Neto et al. $;^{51}$ Gomes et al. $;^{52}$ Luis Silva et al. $;^{5}$; Bordon et al. $;^{54}$ Buruaem et al. ${ }^{55}$

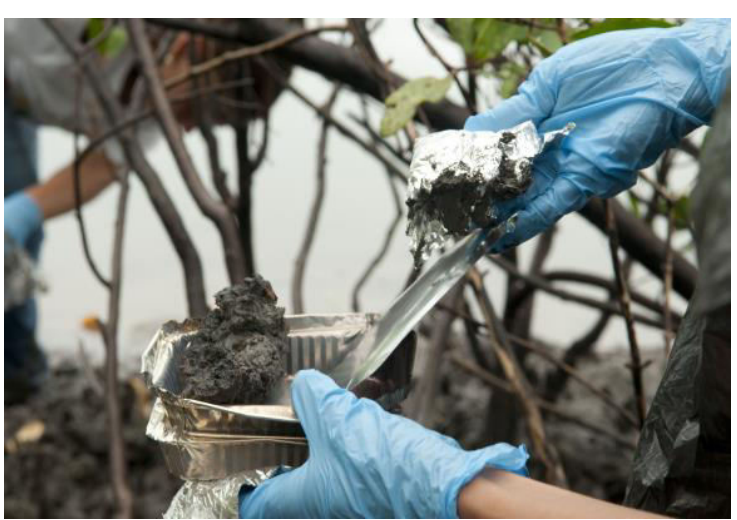

(a)

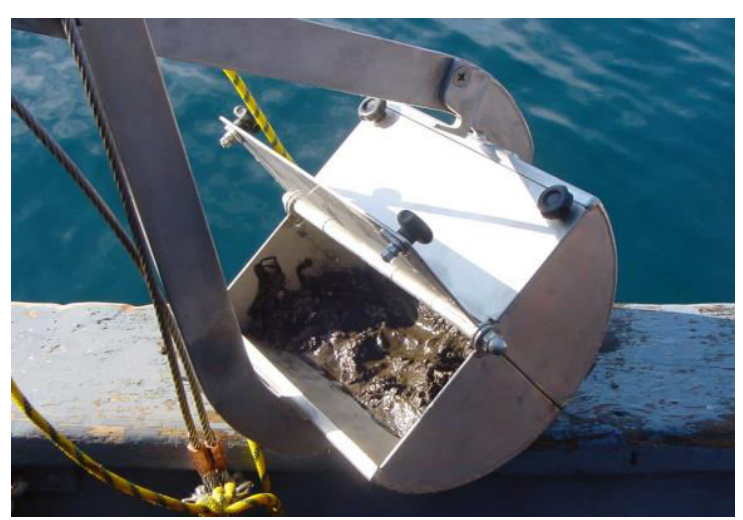

(b)

Figura 8. Coleta de amostras de sedimento em região de mangue em (a) e de sedimento submerso em (b), no entorno da BTS

De uma maneira geral, os níveis de elementos traço encontrados em sedimentos da BTS $^{33,35,37,39,46}$ quando comparados aos valores encontrados em outras baías brasileiras tais como Baía de Guanabara, ${ }^{49-51}$ Baía de Sepetiba, ${ }^{52}$ Estuário $^{53,54}$ e Porto de Santos $^{55}$ são bem inferiores. Esse fato sugere que a BTS é menos impactada em termos de metais do que as demais baías (Guanabara, Sepetiba e de Santos).

\section{Hidrocarbonetos}

A partir da avaliação de sedimentos e testemunhos na BTS, ${ }^{35,56,57}$ verificou-se que, há algumas décadas, nas regiões de exploração de petróleo, a contaminação era mais expressiva, tendo ocorrido uma melhoria nos períodos mais recentes. Entretanto, observou-se uma tendência de aumento das concentrações e fluxos de HPA na região de Caboto, foz do rio São Paulo, Madre de Deus e Ilha das Fontes. A contaminação petrogênica recente mais 
importante foi detectada nas regiões de Itapagipe, foz do Subaé e Mataripe.

Durante o diagnóstico feito pelo $\mathrm{CRA}^{35}$ na BTS, foram realizadas coletas de material particulado em suspensão e sedimentos, em pontos próximos à área de atividades de exploração de petróleo e vizinhas à RLAM, em cinco tributários (São Paulo, Mataripe, Dom João, Subaé e no canal de São Roque do Paraguaçu). Para o material particulado, os resultados mostraram concentrações mais altas de HPA nos rios Paraguaçu e Mataripe, enquanto o rio Subaé apresentou as menores concentrações. HPA de origem petrogênica predominaram principalmente nos rios Dom João e Mataripe. Entretanto, este estudo refere-se a um número muito pequeno de amostras e, portanto, não pode ser considerado como representativo das regiões amostradas.

Com relação ao sedimento, os resultados indicaram que não são esperados efeitos deletérios devido aos níveis de hidrocarbonetos presentes. Porém, os sedimentos das áreas leste e norte da baía, correspondente à área adjacente a Mataripe e ao Porto de Aratu, apresentaram-se mais contaminados por hidrocarbonetos do que as outras regiões da BTS. Em Aratu ressalta-se a influência de atividades portuárias e em Mataripe a indústria petrolífera. Existem evidências científicas da toxicidade e da ação carcinogênica de HPA alquilados, ${ }^{57-59}$ apesar de ainda não se dispor na literatura de níveis máximos recomendados. Os valores de HPA totais no sedimento variaram de abaixo do limite de deteç̧ão a $2.226 \mathrm{ngg}^{-1} .{ }^{44} \mathrm{Em}$ ambientes com introdução crônica de HPA (Tabela 5) foram observados valores de até $2.015 \mu \mathrm{g} \mathrm{g}^{-1}$ no Estuário de Santos ${ }^{60}$ ou 1.760 $\mu \mathrm{g} \mathrm{g}{ }^{-1}$ na Baía de Hong Kong. ${ }^{61}$ Algumas áreas do infralitoral da BTS exibiram concentrações relativamente altas de HPA (Itapagipe, Aratu, Mataripe e foz do Subaé), que podem oferecer algum risco à biota. ${ }^{35}$

Tabela 5. Concentração mínima e máxima de HPA e MCNR em sedimentos da BTS e outras localidades

\begin{tabular}{|c|c|c|}
\hline Local & $\operatorname{MCNR}^{\mathrm{a}}\left(\mu \mathrm{g} \mathrm{g}^{-1}\right)$ & HPA totais $\left(\mathrm{ng} \mathrm{g}^{-1}\right)$ \\
\hline BTS - infralitoral ${ }^{35}$ & $<\mathrm{LD}-1.267$ & $<\mathrm{LD}-2.226$ \\
\hline BTS (Mataripe) ${ }^{62,63}$ & $<L D-189$ & $8,29-4.163$ \\
\hline $\mathrm{BTS}^{38}$ & $<L D-324$ & $<$ LD - 151.960* \\
\hline BTS - mesolitoral ${ }^{35}$ & - & $1.679-23.161$ \\
\hline BTS (rio São Paulo) & $18,7-277$ & $345-2.500$ \\
\hline BTS (rio Paraguaçu) ${ }^{36}$ & - & $<L D-314$ \\
\hline BTS (rio Caípe) ${ }^{58}$ & - & $30-223$ \\
\hline BTS (rio Caípe) 65 & - & $21,2-89,6$ \\
\hline Estuário de Santos, SP ${ }^{61}$ & $13,2-2.015$ & $22-66.813$ \\
\hline São Sebastião, SP 66 & $<L D-0,99$ & $20,4-200$ \\
\hline Baía de Montevidéu ${ }^{67}$ & $11,1-55,9$ & $1.560-90.444$ \\
\hline Mar Negro ${ }^{68}$ & $1-232$ & $7,2-635$ \\
\hline Baía de Hong Kong ${ }^{61}$ & $4,44-1.760$ & $2,86-4.420$ \\
\hline
\end{tabular}

${ }^{a}$ MCNR = mistura complexa não resolvida.

$<L D=$ abaixo do limite de deteç̧ão;

*Concentração em equivalentes de criseno.

Referências utilizadas para compor essa tabela foram: CRA 2004; ${ }^{35}$ Hatje e Barros; ${ }^{36}$ Silva; $^{47}$ UFBA 1996; ${ }^{38}$ Vondráčeket al.; ${ }^{58}$ Zheng e Richardson; ${ }^{61}$ Venturini et al.; ${ }^{62}$ Venturini et al. ${ }^{63}$ Celino e Queiroz; ${ }^{64}$ SENAI 2006; ${ }^{65}$ Medeiros e Bícego; ${ }^{66}$ Muniz et al.; ${ }^{67}$ e Readman et al. ${ }^{68}$

CRA $^{35}$ mostrou que os produtos pirolíticos (com 4 ou mais anéis aromáticos e baixo grau de alquilação) são mais amplamente dispersos nos sedimentos da BTS do que os 
compostos de origem petrogênica (com 2 e 3 anéis aromáticos e alto grau de alquilação), os quais sedimentam, preferencialmente, nas proximidades de suas fontes. A única área onde os índices mostraram uma contribuição petrogênica substancial foi em Mataripe, onde as concentrações de HPA diminuíram em direção ao centro da baía, o que indica a RLAM como provável fonte destes compostos para a região. Um estudo de toxicidade, usando amostras de sedimentos coletados nas proximidades da RLAM (Ilha das Fontes, Ilha de Madre de Deus, Pati e Mataripe), além de duas estações controle ao sul da baía, ${ }^{69}$ revelou que os valores de concentração obtidos foram comparáveis a locais de contaminação moderada.

As concentrações de HPA totais em Mataripe ${ }^{62,63}$ variam de 8 a $4.163 \mathrm{ng} \mathrm{g}^{-1}$, e a maior concentração foi registrada em um ponto localizado próximo à RLAM. Três pontos apresentaram valores de concentrações em sedimentos acima do TEL. O TEL representa a concentração abaixo da qual se espera que a ocorrência de efeitos adversos aconteça apenas raramente. Os três locais mencionados correspondem à área que fica mais próxima à saída do efluente da refinaria e a uma área de deposição no centro da baía, com predominância de sedimentos pelíticos (argilosos). As concentrações foram similares àquelas observadas em regiões de grande influência urbana e industrial. ${ }^{70,71}$ Segundo Venturini et al., ${ }^{62,63}$ pelos índices usados para determinar a origem dos HPA, a contribuição é uma mistura de compostos petrogênicos e pirolíticos, principalmente derivados da queima de combustíveis fósseis. Esses dados de hidrocarbonetos, associados a outros da comunidade bentônica, mostram que a região central e o setor leste da área de estudo são zonas que apresentam um empobrecimento da fauna bentônica decorrente, principalmente, das maiores concentrações de hidrocarbonetos de origem petrogênica e pirogênica.

Um dos métodos utilizados para diferenciar os hidrocarbonetos do petróleo dos hidrocarbonetos biogênicos é o Índice de Preferência de Carbonos (IPC). Valores de IPC próximos a 1 indicam a presença de hidrocarbonetos do petróleo e valores maiores indicam a predominância de hidrocarbonetos biogênicos. Nos estudos em que foram avaliados os $\mathrm{n}$-alcanos individuais, observou-se que, de um modo geral, a BTS recebe uma grande influência de hidrocarbonetos de origem biogênica. No estudo realizado pelo CRA, o valor médio observado foi de 2,33 e foram poucas as exceções em que o IPC apresentou valores próximos a 1 . No entanto, diversos pontos de coleta exibiram concentrações superiores a $100 \mu \mathrm{g} \mathrm{g}^{-1}$. Os resultados de IPC no material particulado em suspensão indicaram que houve predomínio de material biogênico. $O$ maior valor foi verificado na área sob influência da refinaria, localizada em Mataripe.

No petróleo existem compostos que são difíceis de serem degradados, constituindo a chamada Mistura Complexa Não Resolvida (MCNR) ${ }^{72,73}$ A MCNR é caracterizada por uma mistura de compostos ramificados e cíclicos. Enquanto os compostos com estruturas mais simples degradam-se mais facilmente, essa mistura, além de ser resistente à degradação, tende a acumular-se nos sedimentos. ${ }^{72,74}$ Vale ressaltar que existem fontes naturais associadas a essas misturas, embora pouco comuns. ${ }^{75}$ No rio Paraguaçu, a elevada concentração de alifáticos combinada à ausência de uma MCNR mensurável, indica origem prioritariamente natural destes compostos. Na BTS foram observadas concentrações de MCNR com valores abaixo do limite de detecção até concentrações da ordem de $564 \mathrm{ng} \mathrm{g}^{-1} \cdot{ }^{35}$ A MNCR variou de abaixo do limite de detecção a $189 \mu \mathrm{g} \mathrm{g}^{-1}$, e apenas três amostras não apresentaram esta feição. A MNCR representou entre 60 e 90\% dos hidrocarbonetos alifáticos totais, indicando um alto grau de contribuição antrópica e a presença de resíduos de petróleo degradado. ${ }^{62,63} \mathrm{~A}$ presença de uma MCNR na estação do rio Mataripe é um forte indício da presença de hidrocarbonetos de origem petrogênica. 
A contaminação por compostos orgânicos na BTS pode ser, assim, resumida: para o material particulado em suspensão na água, as concentrações mais altas de HPA, principalmente de origem petrogênica predominaram nos rios Mataripe e Dom João, que são áreas próximas à refinaria RLAM. No sedimento, as áreas leste e norte da BTS, nas regiões desde Mataripe (próximo à refinaria) até o porto de Aratu, apresentam nível elevado de contaminação em relação às outras áreas da BTS. A principal fonte de contaminação por HPA na porção norte é encontrada na área adjacente à refinaria. Mas, existem outras fontes menores, próximas ao rio Dom João, Ilha de Maria Guarda, porto de Aratu e rio Subaé, que contribuem para a contaminação local. A contaminação por HPA, registrada na foz do rio Subaé, em Mataripe e nas Baías de Itapagipe e Aratu, pode oferecer risco à biota. Efeitos da contaminação foram verificados em trabalhos feitos com a macrofauna bêntica na região central e leste da BTS. O estudo mostrou empobrecimento da fauna bentônica em decorrência da contaminação petrogênica e pirogênica.

\subsection{Bivalves}

O consumo de pescados, especialmente de invertebrados na BTS, é a principal fonte de proteína animal para as comunidades ribeirinhas. A coleta de mariscos e a pesca artesanal são uma importante fonte de renda para mais de 15000 famílias que habitam o Recôncavo. Visto a importância de algumas espécies biológicas para a região, vários estudos foram realizados na BTS para a determinação de metais em pescados. Alguns organismos que acumulam metais nos seus tecidos podem ser utilizados como biomonitores.

A quantidade de metal acumulada em um organismo representa todo 0 metal incorporado e/ou excretado pelo organismo ao longo do seu tempo de vida. ${ }^{76} \mathrm{~A}$ acumulação dos metais em um organismo biomonitor é um indicativo de que o metal pode estar sendo biodisponibilizado ou não a partir do ambiente em que vive. Os moluscos bivalves (exemplo, sururu e ostra) têm sido amplamente utilizados em programas de biomonitoramento. ${ }^{77-79} \mathrm{Na}$ América do Sul, a ostra da espécie Crassostrea rhizophorae é uma boa biomonitora de metais. ${ }^{80}$ No caso da BTS, os organismos mais utilizados nos estudos de metais foram os bivalves: chumbinho/papa fumo (Anomalocardia brasiliana), ostra (Crassostrea rhizophorae), pé de galinha (Macoma constricta); sururu (Mytella guianensis), sururu de pedra (Brachidontes exustus) e a lambreta (Lucina pectinata). Embora a maior parte dos estudos desenvolvidos na BTS tenha empregado organismos bivalves, alguns trabalhos recentes utilizaram outras espécies da biota, como peixes, caranguejos, corais e poliquetas. $^{35,81-83} \mathrm{Na}$ figura 9 é possível observar a coleta de amostras de ostra e na figura 10 são apresentadas algumas espécies de bivalves encontrados na BTS.

Comparando-se os teores de metais na biota estudada, pode-se observar que os organismos respondem de maneira diversa aos teores de metais no ambiente. Isso se deve ao fato de cada espécie possuir uma estratégia de alimentação, taxa de crescimento, eficiência de assimilação/eliminação de metais e habitat específicos. A tabela 6 mostra as concentrações de metais encontradas em bivalves da BTS. Para a avaliação do nível de contaminação por metais na biota, as concentrações obtidas nos diversos estudos foram comparadas aos critérios da legislação brasileira. Esses critérios utilizam dois instrumentos para estabelecer limites de tolerância máxima de contaminantes inorgânicos em alimentos: Decreto $n^{\circ} 55.871$, de 26 de março de 1965 e a Portaria $n^{\circ}$ 685, de 27 de agosto de 1998, da Agência Nacional de Vigilância Sanitária (ANVISA). Os resultados mostraram que ocorreu violação da legislação para todo o conjunto de metais avaliados. Em ordem decrescente, os metais com maior número de violações da legislação brasileira e/ou NOAA foram $\mathrm{Cu}>\mathrm{Zn}>\mathrm{Pb}>\mathrm{Cd}$ $>$ As $>\mathrm{Hg}$. Para os bivalves, a contaminação foi principalmente decorrente de $\mathrm{Cu}, \mathrm{Zn}$ e $\mathrm{Cd}$. 
Já para os peixes destacaram-se as altas concentrações de As e $\mathrm{Hg}$. Um estudo recente que avaliou os teores dos metais em peixes, relatou que oito das doze localidades amostradas apresentaram amostras de peixes com teores de $\mathrm{Hg}$ acima do permitido pela legislação. ${ }^{81}$ As espécies estudadas foram a tainha, a arraia, o corró, a sardinha e o linguado. $O$ rio Subaé e a área adjacente a sua desembocadura na BTS, a Baía de Aratu e sua região portuária, bem como as áreas próximas a Mataripe e Caboto, são os locais mais críticos em termos de contaminação da biota.

Estudo recente mostrou que bivalves da porção nordeste da BTS apresentam altas concentrações de As, $\mathrm{Zn}$, Se, $\mathrm{Cu}$ e $\mathrm{Pb}^{.84} \mathrm{Em}$ virtude dos elevados teores de metais observados em amostras biológicas da $\mathrm{BTS}^{35,84-86}$ foi realizada uma análise preliminar de risco, não carcinogênico e carcinogênico, associado ao consumo do pescado pelas comunidades do entorno da
BTS ${ }^{81,84} \mathrm{O}$ estudo foi baseado na exposição das populações adulta e infantil ao pescado contaminado, e seguiu o princípio da precaução: proteger a população mais exposta a qualquer risco potencial. Os resultados revelaram que os crustáceos apresentaram os menores riscos ao consumo, seguidos pelos bivalves e peixes. 0 grupo dos bivalves foi o que apresentou risco relevante para um maior número de metais $(\mathrm{Cu}, \mathrm{Fe}, \mathrm{Cr}$, $\mathrm{Pb}$ e $\mathrm{Hg}$ ), em virtude dos teores elevados encontrados para o pé de galinha.

Diante do que foi exposto sobre a contaminação de metais na biota, cabe enfatizar que os locais mais críticos da BTS, com histórico de contaminação são: Subaé, Mataripe, Caboto, Baía de Aratu e regiões portuárias. Os bivalves pé de galinha, ostra e chumbinho apresentam maior acumulação de metais em relação aos crustáceos e peixes. Os bivalves oferecem um risco mais elevado, quando consumidos diariamente em grande quantidade.

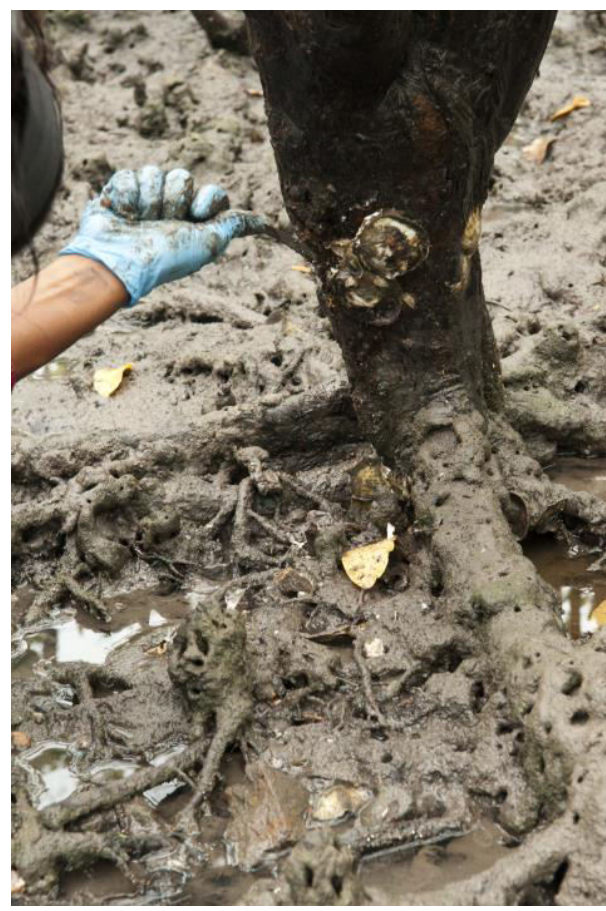

Figura 9. Coleta de amostras de ostra no entorno da BTS 


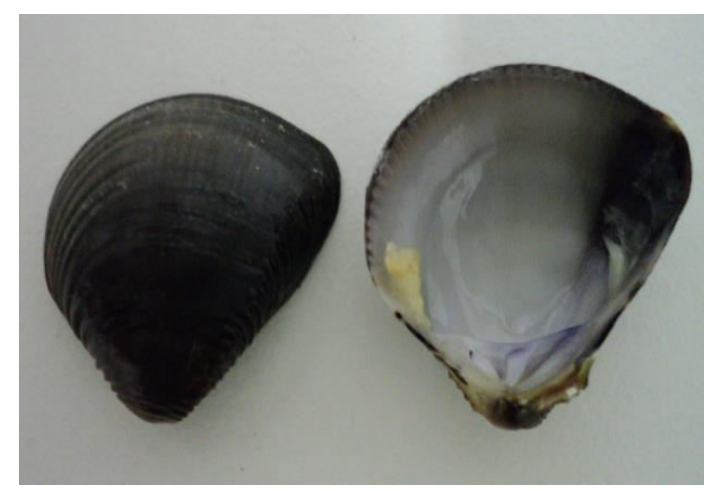

(a)

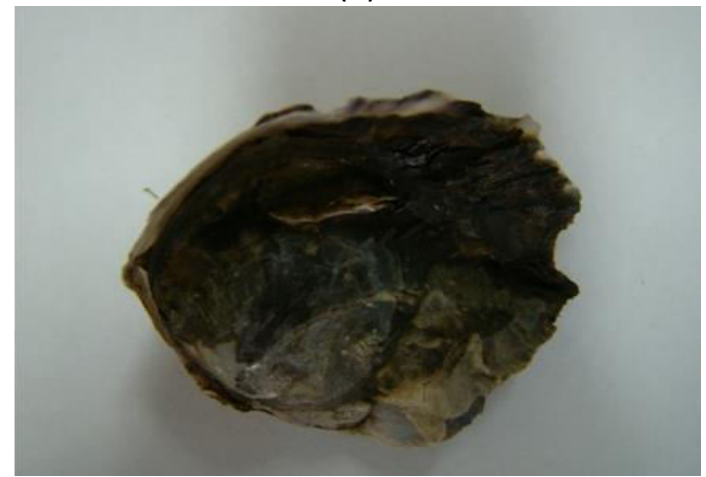

(c)

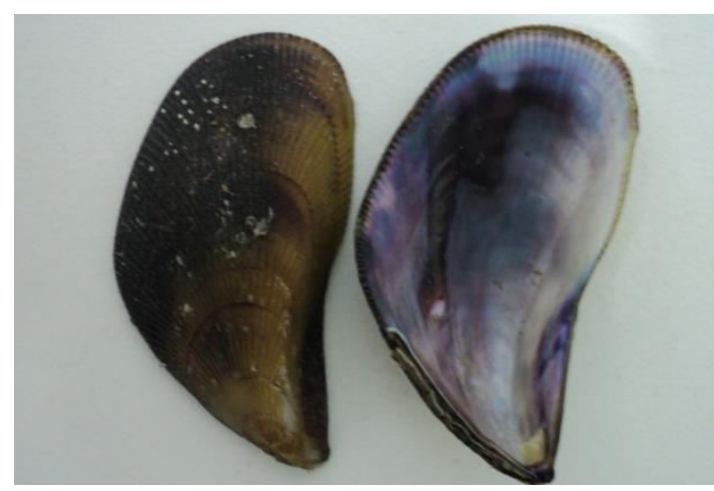

(b)

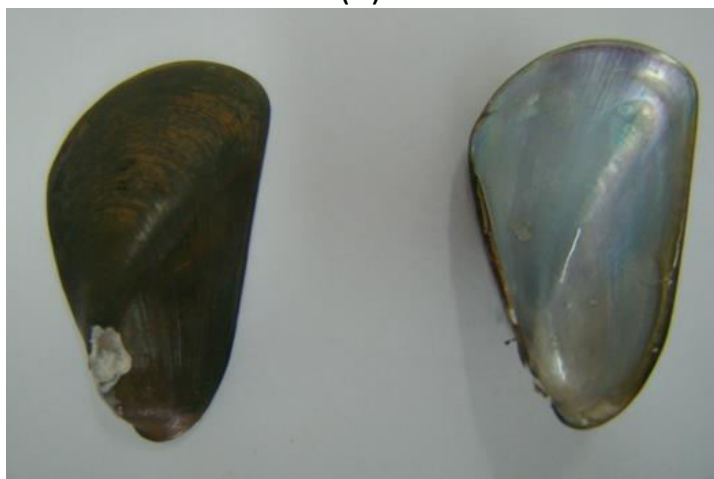

(d)

Figura 10. Exemplares de alguns organismos bivalves encontrados na BTS. Em (a) Anomalocardia brasiliana, conhecida como chumbinho ou papa fumo; em (b) Brachidontes exustus, conhecida como sururu de pedra; (c) Crassostrea rhizophorae, conhecida como ostra de mangue ou ostra e (d) Mytella guyanensis, conhecida como sururu, marisco de mangue ou mexilhão

\subsection{Algas}

Embora a BTS apresente uma flora relativamente rica para algas, ${ }^{89-91}$ a sua viabilidade como biomonitores de metais traço não vem sendo explorada. Apenas um estudo foi realizado, ${ }^{92}$ empregando Padina gymnospora e Sargassum sp., coletadas entre agosto de 2000 e fevereiro de 2001 em três áreas (Tapera, Paramana e Botelho) da BTS.
Recentemente, foi desenvolvido um trabalho visando estudar a distribuição dos elementos As, Ba, Cd, Co, Cr, Cu, Li, Mn, Ni, Pb, V e Zn em dez espécies de macroalgas (Acanthophora spicifera, Bostrychia montagnei, Dictyopteris jamaicensis, Padina spp., Sargassum spp., Ulva lactuca, Bryopsis plumosa, Caulerpa racemosa, Caulerpa scalpelliformis e Penicillus capitatus) (Figura 11)..$^{93}$ 
Tabela 6. Concentração mínima e máxima de metais ( $\mu \mathrm{g} \mathrm{g}^{-1}$, peso seco) em tecidos de organismos biomonitores coletados na Baía de Todos os Santos, BA

\begin{tabular}{|c|c|c|c|c|c|c|c|c|c|c|c|}
\hline \multirow{2}{*}{$\begin{array}{l}\text { Bivalve biomonitor } \\
\text { (espécie) }\end{array}$} & \multicolumn{2}{|c|}{ As } & \multicolumn{2}{|c|}{$\mathrm{Cd}$} & \multicolumn{2}{|c|}{$\mathrm{Cu}$} & \multicolumn{2}{|c|}{$\mathrm{Pb}$} & \multicolumn{2}{|c|}{$\mathrm{Zn}$} & \multirow[t]{2}{*}{ Fonte } \\
\hline & Mín. & Máx. & Mín. & Máx. & Mín. & Máx. & Mín. & Máx. & Mín. & Máx. & \\
\hline \multirow[t]{5}{*}{$\begin{array}{l}\text { Chumbinho/Papa fumo } \\
\text { (Anomalocardia brasiliana) }\end{array}$} & 2,06 & 4,3 & 0,86 & 4,11 & 3,25 & 26,4 & 1,36 & 71,8 & - & - & 81 \\
\hline & - & - & 0,99 & 8,15 & 8,9 & 24,6 & 0,14 & 2,07 & 60,5 & 66,9 & 87 \\
\hline & - & - & 0,02 & 0,02 & - & - & - & - & - & - & 88 \\
\hline & - & - & 2,71 & 8,29 & 225 & 526 & 4,5 & 6,6 & 1.89 & 4.733 & 86 \\
\hline & $<\mathrm{LD}$ & 14,0 & $<\mathrm{LD}$ & 0,59 & 1,03 & 48,7 & $<\mathrm{LD}$ & 6,76 & 46,9 & 82,2 & 84 \\
\hline \multirow[t]{3}{*}{$\begin{array}{c}\text { Ostra } \\
\text { (Crassostrea rhizophorae) }\end{array}$} & $<L D$ & 13,2 & & 13,7 & 28,4 & 602 & $<L D$ & 9,89 & 846 & 2976 & 84 \\
\hline & - & - & 3,9 & 8,11 & 31,8 & 100 & 0,25 & 0,99 & 1.141 & 1.863 & 87 \\
\hline & - & - & 2,95 & 4,13 & 1150 & 1984 & 0,49 & 0,69 & 2.231 & 3.781 & 85 \\
\hline $\begin{array}{c}\text { Sururu } \\
\text { (Mytella guianensis) }\end{array}$ & 1,44 & 12,5 & $<L D$ & 0,56 & 10,8 & 102 & 4,45 & 9,27 & 50,8 & 182 & 84 \\
\hline $\begin{array}{c}\text { Sururu } \\
\text { (Mytella guianensis) }\end{array}$ & - & - & 0,1 & 0,97 & 13,9 & 68,1 & 0,477 & 3,75 & 49,9 & 78,5 & 87 \\
\hline \multirow[t]{3}{*}{$\begin{array}{c}\text { Pé de galinha } \\
\text { (Macoma constricta) }\end{array}$} & 2,9 & 11,7 & 0,012 & 0,33 & 1,8 & 116 & 0,35 & 3,7 & 3,4 & 165 & 35 \\
\hline & - & - & 0,18 & 1,22 & 9,86 & 123 & 5,3 & 25,2 & - & - & 81 \\
\hline & - & - & 0,01 & 0,98 & 16,9 & 194 & 0,228 & 4,68 & 43,3 & 61,7 & 87 \\
\hline
\end{tabular}

$\angle L D=$ abaixo do limite de deteç̧ão.

As referências usadas para compor essa tabela foram: CRA 2004; ${ }^{35}$ CRA 2005; ${ }^{81}$ Souza et al. $;^{84}$ 2011; Peso-Aguiar e Verani; ${ }^{85}$ Wallner-Kersanach et al.; ${ }^{86}$ Gonçalves $^{87}$ e Amado-Filho et al. ${ }^{88}$

$\mathrm{Na}$ figura 12 estão apresentados os resultados obtidos para $\mathrm{Cr}, \mathrm{Cu}, \mathrm{As}, \mathrm{Cd}$ e $\mathrm{Pb}$ nas espécies Padina spp., $C$. scalpelliformis, $C$. racemosa, A. spiciferae $P$. capitatus coletadas na llha de Bimbarras. É possível verificar uma alta variabilidade de concentrações de metais entre espécies diferentes do mesmo local de amostragem. De fato, os níveis de metal são dependentes tanto de parâmetros bióticos quanto de diferenças estruturais entre as espécies de algas. Além disso, cada espécie de macroalga tem afinidades diferentes para os elementos traço, o que pode refletir a concorrência entre os elementos para sítios de ligação ou captação das macroalgas. ${ }^{92-94}$

Vale ressaltar que nas amostras de Padina spp., as concentrações apresentaram a seguinte tendência em ordem decrescente (alguns resultados estão nas Figuras 13 e 14):

- $\mathrm{Co}>\mathrm{Mn}>\mathrm{V}>\mathrm{Ba}>\mathrm{Cr}>\mathrm{Zn}>\mathrm{As}>\mathrm{Cu}>$ $\mathrm{Ni}>\mathrm{Pb}>\mathrm{Li}>\mathrm{Cd}$ em Itaparica;
- $\mathrm{Mn}>\mathrm{Co}>\mathrm{Ba}>\mathrm{Zn}>\mathrm{As}>\mathrm{V}>\mathrm{Ni}>\mathrm{Cr}>$ $\mathrm{Cu}>\mathrm{Li}>\mathrm{Pb}>\mathrm{Cd}$ em Salinas da Margarida;

- $\mathrm{Mn}>\mathrm{Co}>\mathrm{Zn}>\mathrm{Cu}>\mathrm{Ba}>\mathrm{V}>\mathrm{As}>\mathrm{Ni}>$ $\mathrm{Cr}>\mathrm{Li}>\mathrm{Pb}>\mathrm{Cd}$ em llha de Maré;

- $\mathrm{Mn}>\mathrm{Co}>\mathrm{Cu}>\mathrm{Zn}>\mathrm{Ba}>\mathrm{V}>\mathrm{Ni}>\mathrm{Pb}>$ As $>\mathrm{Cr}>\mathrm{Li}>\mathrm{Cd}$ em Caboto;

- $\mathrm{Mn}>\mathrm{Co}>\mathrm{Zn}>\mathrm{Ba}>\mathrm{Cu}>\mathrm{V}>\mathrm{As}>\mathrm{Ni}>$ $\mathrm{Cr}>\mathrm{Cd}>\mathrm{Pb}>\mathrm{Li}$ em Bimbarras.

Comparando-se estes resultados com outros referentes às coletas realizadas na Praia do Botelho, Ilha de Maré, por Amado Filho et $a l^{93}$ verificou-se que, dez anos depois, $\mathrm{Mn}, \mathrm{Ni}$ e $\mathrm{Pb}$ apresentaram concentrações inferiores em Padina spp. Porém, o contínuo monitoramento é importante para acompanhar a variação da concentração dos elementos presentes no meio. 


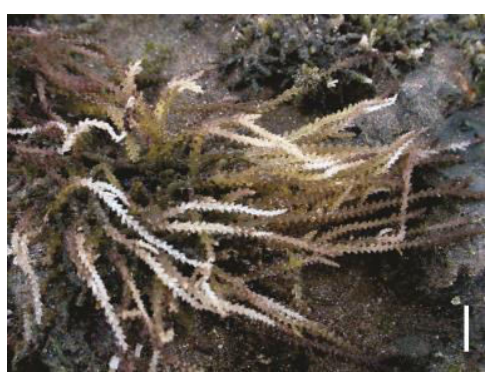

(a)

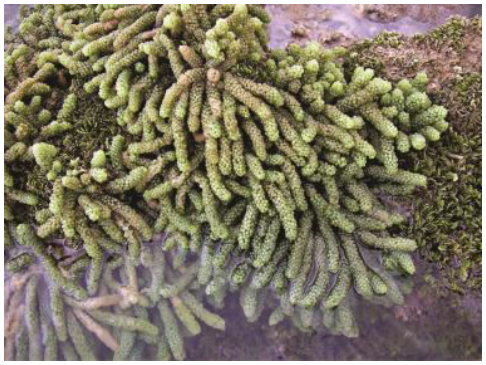

(d)

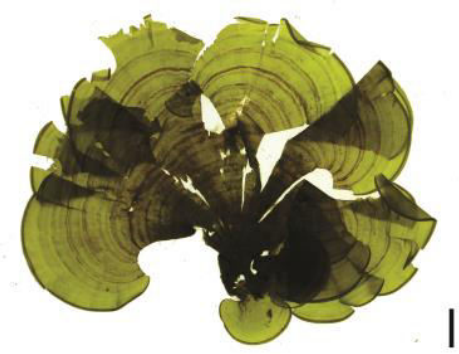

(g)

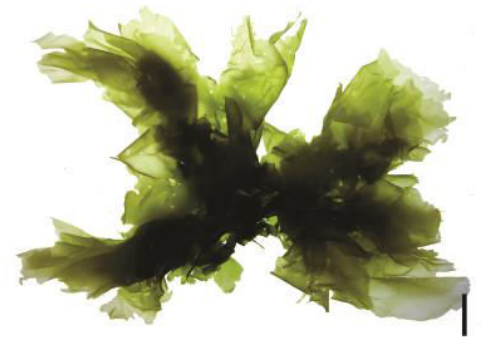

(j)

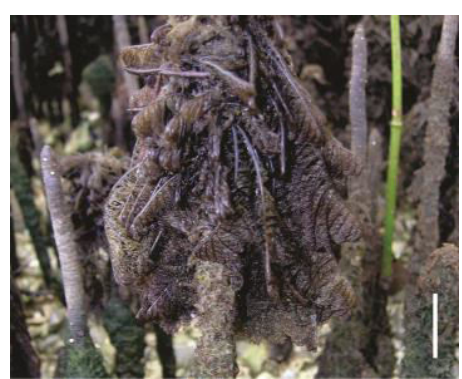

(b)

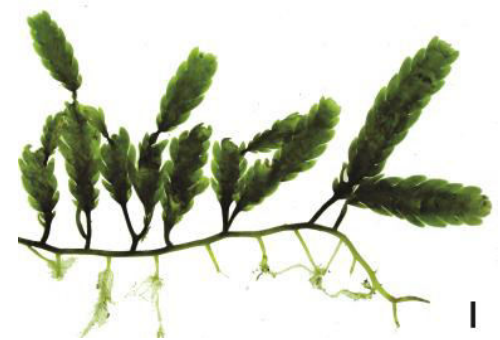

(e)

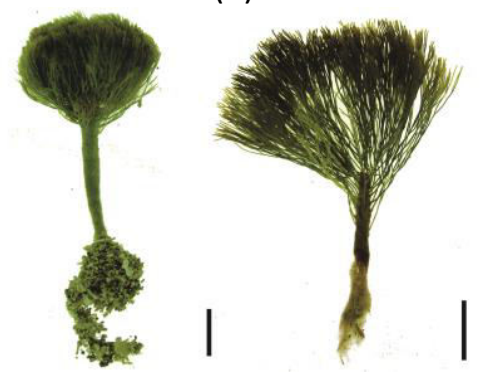

(h)

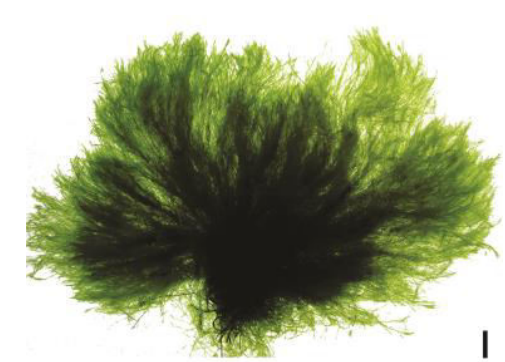

(c)

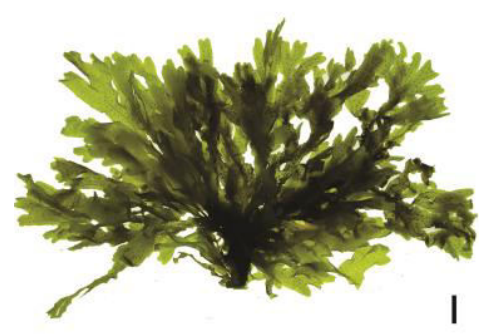

(f)

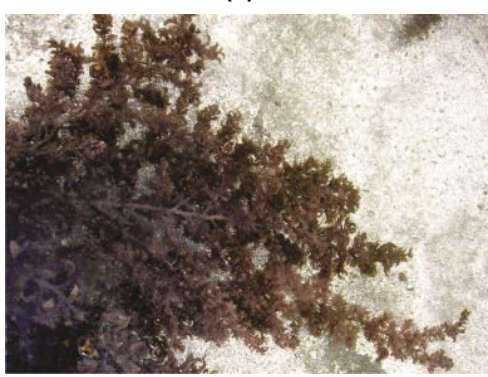

(i)

Figura 11. Aspecto geral de espécies de algas encontradas na BTS, (a) Acanthophora spicifera, (b) Bostrychia montagnei, (c) Bryopsis plumosa, (d) Caulerpa racemosa, (e) Caulerpa scalpelliformis, (f) Dictyopteris jamaicensis, (g) Padina boergesenii, (h) Penicillus capitatus, (i) Sargassum spp., (j) Ulva lactuca. A escala que aparece na lateral de cada foto corresponde a um centímetro 


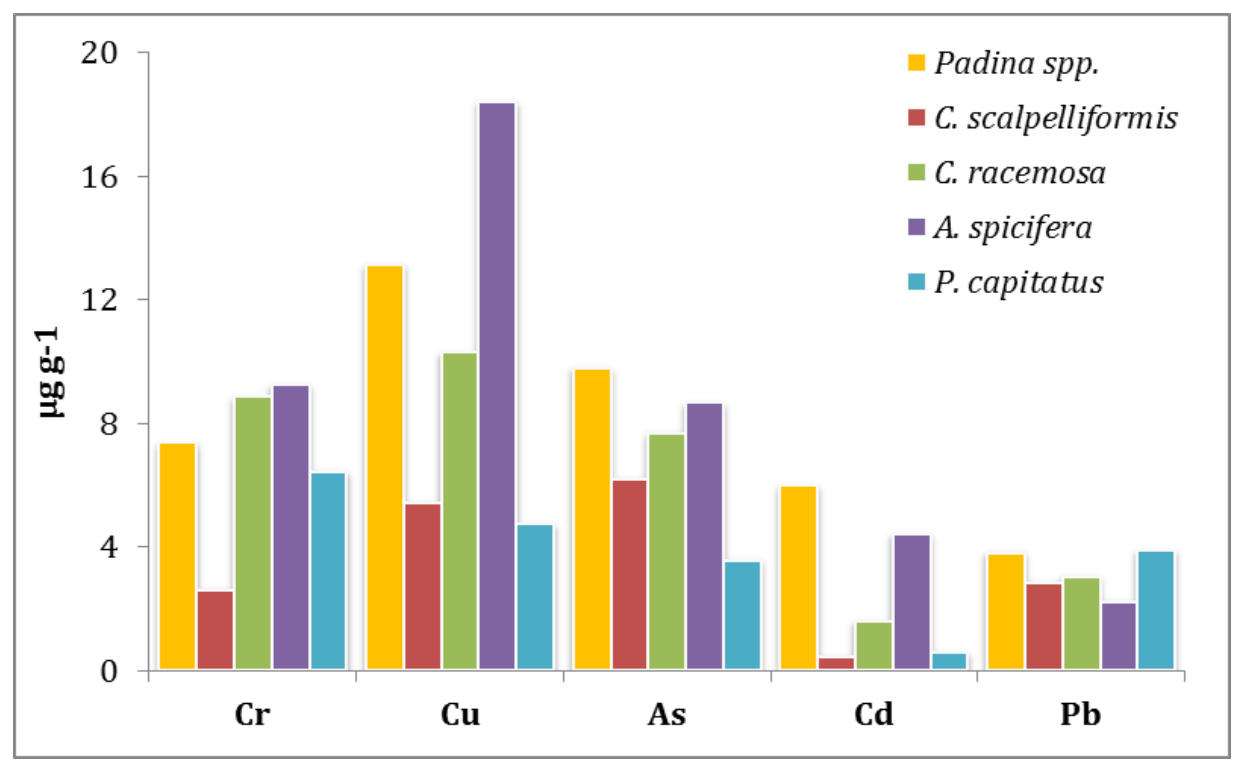

Figura 12. Concentração de $\mathrm{Cr}, \mathrm{Cu}, \mathrm{As}, \mathrm{Cd}$ e $\mathrm{Pb}$ em algas coletadas na llha de Bimbarras, $\mathrm{BTS}$

Fatores físico-químicos como variação da concentração do metal no ambiente, interação entre o analito e outros elementos, salinidade, $\mathrm{pH}$, dentre outros, podem influenciar no diagnóstico dos resultados encontrados. Diante disso, sugere-se uma ampliação dos estudos para conhecer melhor e definir possíveis padrões nas variações de concentração dos elementos traço em macroalgas na região.

A viabilidade das algas atuarem como biomonitores para hidrocarbonetos foi investigada em um estudo preliminar (dados não publicados). Foram identificados $\mathrm{e}$ quantificados alcanos lineares $\mathrm{C}_{18}$ a $\mathrm{C}_{24}$ e um alcano isoprênico (pristano) em cinco diferentes espécies de algas marinhas:
Caulerpa scalpelliformis, Ulva lactuca e Sargassum stenophyllum, Hypneamu sciformis e Padina boergesenii coletadas em Madre de Deus. Os resultados indicam a presença de todos os hidrocarbonetos testados, com concentrações elevadas de pristano para as algas Hypneamu sciformis e Padina boergesenii, enquanto nas espécies Caulerpa scalpelliformis, Ulva lactuca e Sargassum stenophyllumo hidrocarboneto alicíclico de maior concentração foi o $C_{18}$ (Figura 15). Tais resultados apontam para a possibilidade do monitoramento de hidrocarbonetos petrogênicos utilizando algas marinhas como biomonitores de contaminação. 


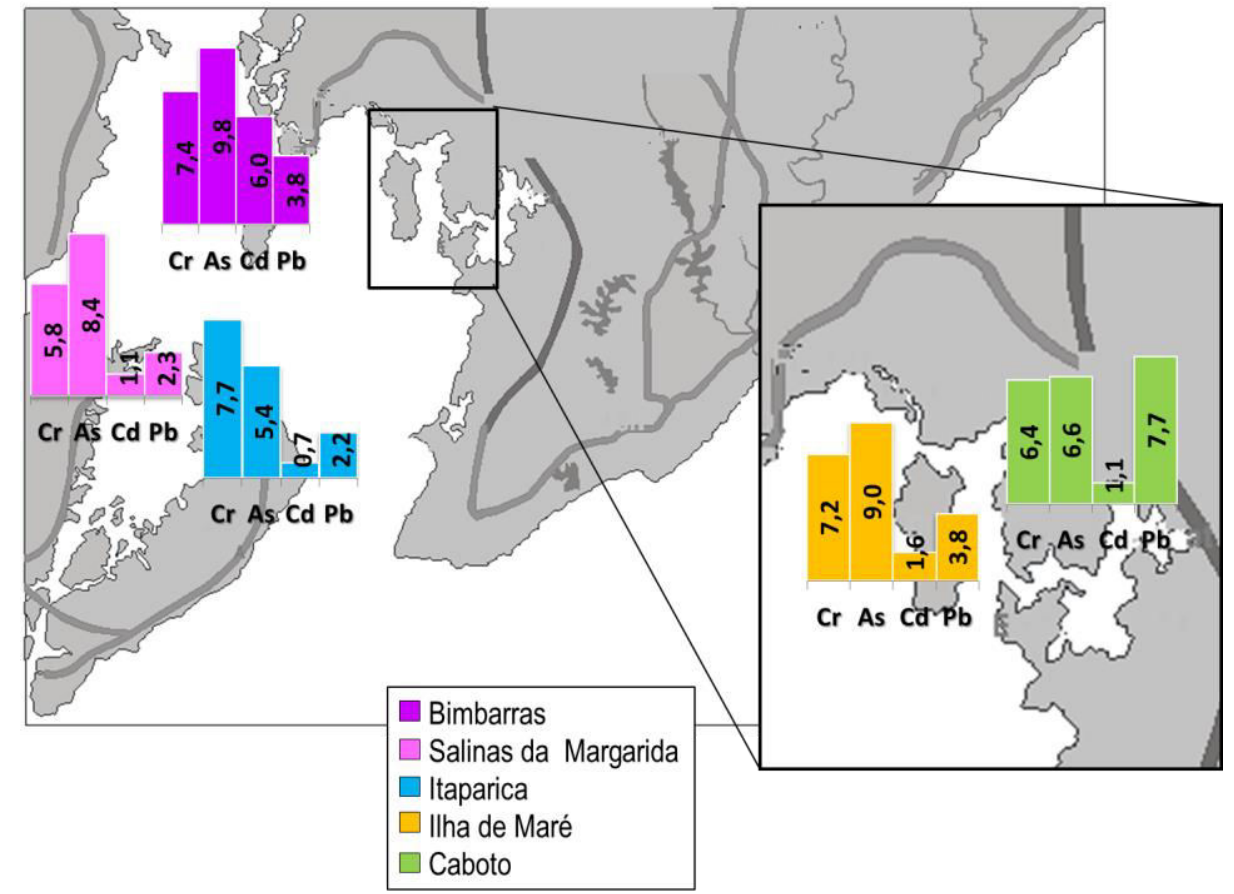

Figura 13. Concentrações de $\mathrm{Cr}$, As, $\mathrm{Cd}$ e $\mathrm{Pb}\left(\mu \mathrm{g} \mathrm{g}^{-1}\right.$, peso seco) em amostras de Padina spp. coletadas no entorno da BTS

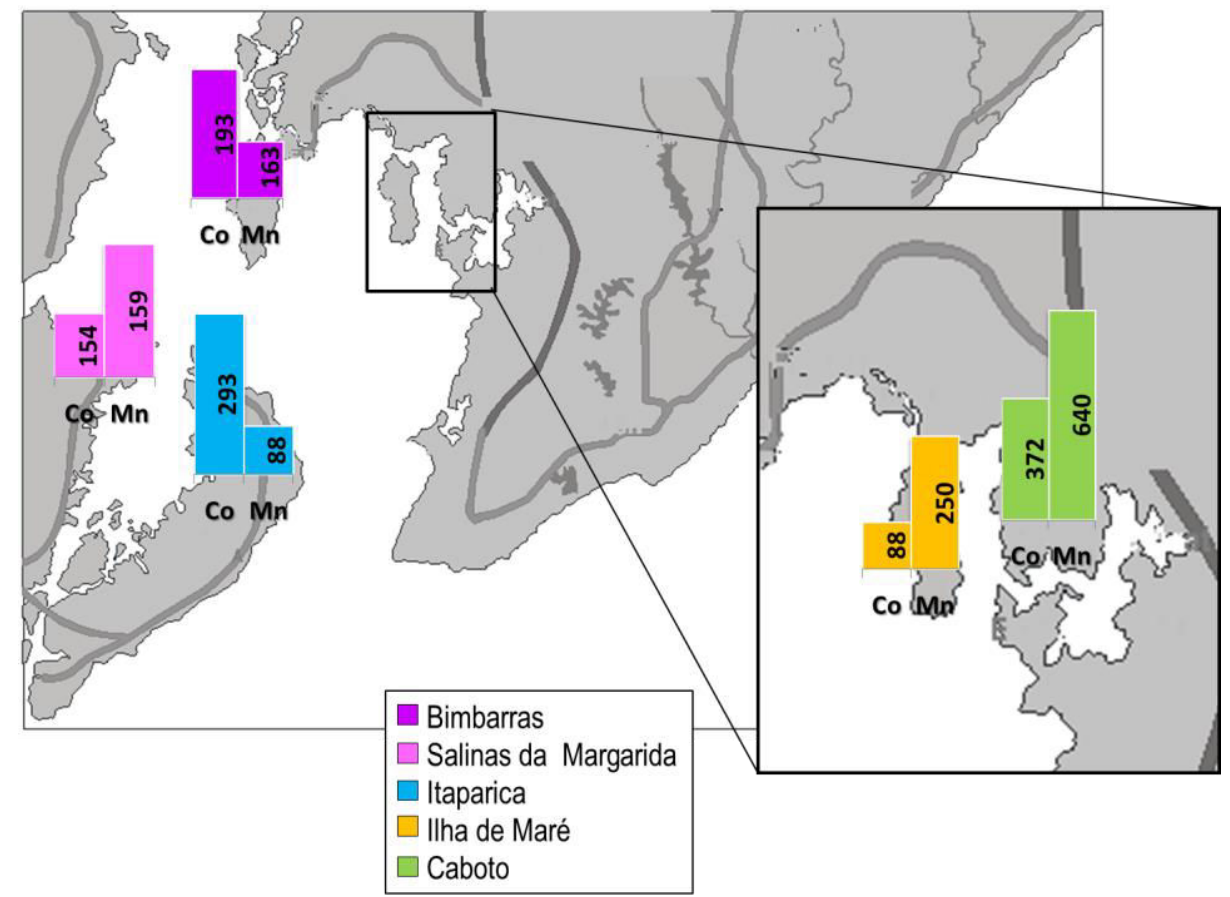

Figura 14. Concentrações de Co e $\mathrm{Mn}$ ( $\mu \mathrm{g} \mathrm{g}^{-1}$, peso seco) em amostras de Padina spp. coletadas no entorno da BTS 


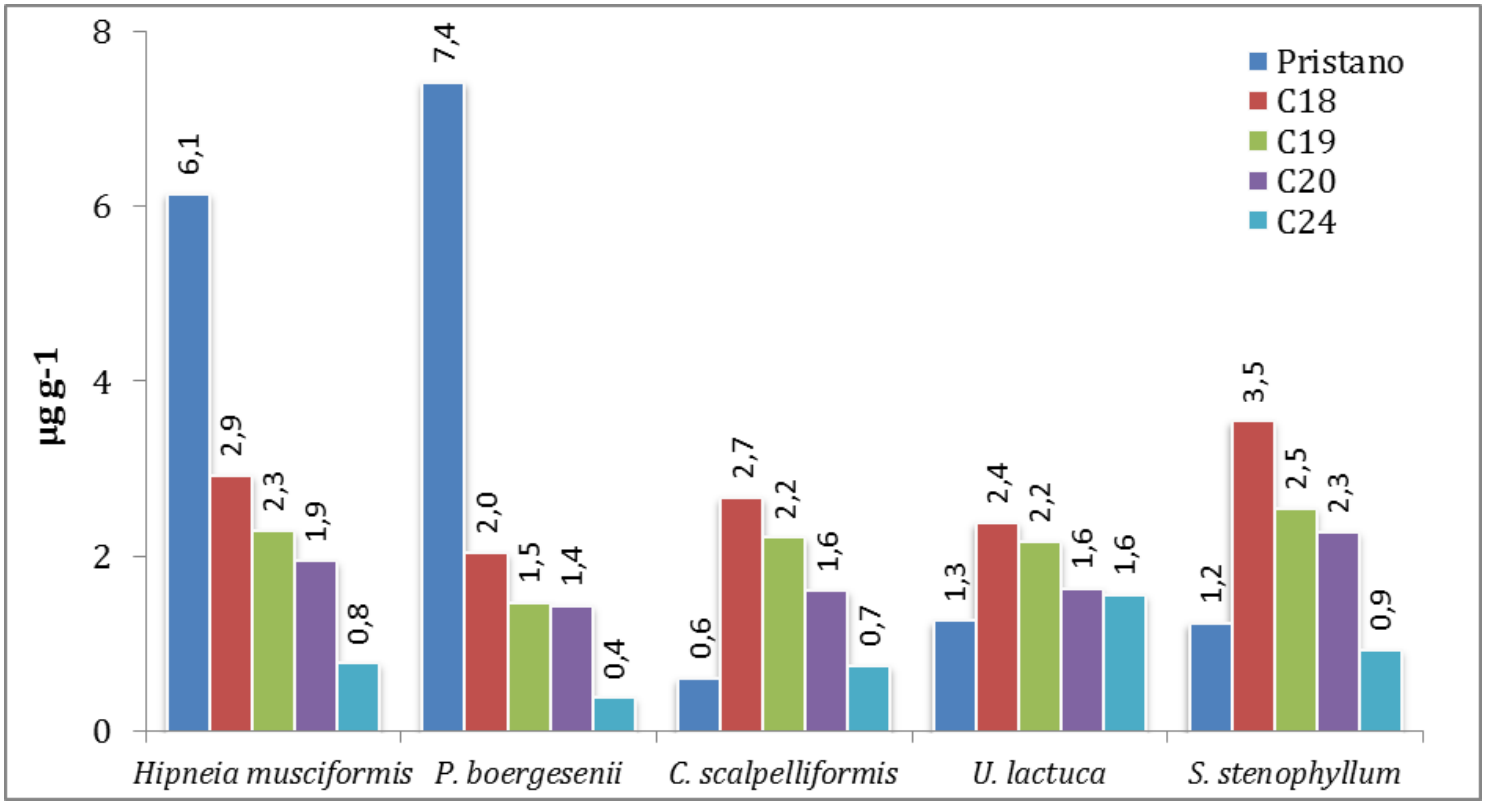

Figura 15. Concentrações de alcanos $\left(\mu \mathrm{g} \mathrm{g}^{-1}\right)$ encontrados em espécies de algas da BTS

\section{Conclusões}

De acordo com tudo que foi discutido até o momento, em várias regiões da Baía de Todos os Santos, o material particulado atmosférico, material particulado em suspensão, algas, sedimentos e biota encontram-se enriquecidos por elementos traço e por contaminantes orgânicos (nalcanos e HPA) em níveis de concentração acima do considerado "background" ou natural. Logo, as contribuições antrópicas (descargas de efluentes industriais e domésticos, extração de petróleo, processos de geração de energia, emissão veicular e atividades portuárias) parecem realmente ter contribuído para os níveis de contaminantes encontrados na BTS hoje. Apesar disso, se comparados os níveis de contaminantes presentes na BTS com os teores encontrados em outras baías, tais como a Baía de Guanabara, a Baía de Santos e a Baía de Sepetiba, a BTS, principalmente na sua porção sul e sudoeste, apresenta-se relativamente bem preservada. Entretanto, os estudos disponíveis na literatura sobre a BTS são ainda relativamente escassos para se ter uma boa compreensão dos impactos antrópicos sofridos por ela. Até agora não foram reportados estudos sistematizados, de longos períodos de tempo e com um maior número de contaminantes, na tentativa de avaliar variações espaciais e temporais e a transferência de materiais nas diferentes interfaces (atmosferaoceano, oceano-continente, atmosferacontinente-oceano). Novos e mais abrangentes estudos sobre a BTS são necessários no futuro.

\section{Agradecimentos}

Os autores agradecem ao Instituto Nacional de Ciência e Tecnologia de Energia e Ambiente (INCT E\&A); ao Conselho Nacional de Desenvolvimento Científico e Tecnológico (CNPq) e a Fundação de Amparo à Pesquisa do Estado da Bahia (FAPESB) pelo apoio financeiro.

\section{Referências Bibliográficas}

${ }^{1}$ Sítio da US EPA, United States Environmental Protection Agency, Disponível 
em: 〈http://www.epa.gov $>$, Acesso em: 18 Agosto 2012.

${ }^{2}$ Miller, G. T.; Spoolman, S. Environmental Science, 14a. ed., Brooks/Cole: USA, 2012.

${ }^{3}$ da Rocha, G. O.; Allen, A. G.; Cardoso, A. A. Environ. Sci. Technol. 2005, 39, 5293. [CrossRef]

${ }^{4}$ Cirano, M.; Lessa, G. C. Braz. J. Geophys. 2007, 25, 363.

${ }^{5}$ Hatje, V.; Bícego, M. C.; Carvalho, G. C.; de Andrade, J. B. Em Baía de Todos os Santos: aspectos oceanográficos; Hatje, V.; de Andrade, J. B., eds.; Edufba: Salvador, 2009, cap. 7.

${ }^{6}$ Peso-Aguiar, M. C.; Smith, D. H.; Assis, R. C. F.; Santa-Isabel, L. M.; Peixinho, S.; Gouveia, E. P.; Almeida, T. C. A.; Andrade, W. S.; Carqueija, C. R. G.; Kelmo, F.; Carrozzo, G.; Rodrigues, C. V.; Carvalho, G. C.; Jesus, A. C. S. Aquat. Ecosyst. Health Mgmt. 2000, 3, 459. [CrossRef]

${ }^{7}$ Tsai, Y. I.; Kuo, S. -C.; Lin, Y. -H. Atmos. Environ. 2003, 37, 3401. [CrossRef]

${ }^{8}$ Pallarés, S.; Vicente, A. B.; Jordán, M. M.; Sanfeliu, T. Water Air Soil Pollut. 2007, 180, 51. [CrossRef]

${ }^{9}$ Tsopelas, F.; Tsakanika, L.-A.; OchsenkühnPetropoulou, M. Microchem. J. 2008, 89, 165. [CrossRef]

${ }^{10}$ Allen, A. G.; Nemitz, E.; Shi, J. P.; Harrison, R. M.; Greenwood, J. C. Atmos. Environ. 2001, 35, 4581. [CrossRef]

${ }^{11}$ Birmili, W.; Allen, A. G.; Bary, F.; Harrison, R. M. Environ. Sci. Technol. 2006, 40, 1144. [CrossRef]

${ }^{12}$ Macedo, S. M.; dos Santos, D. C.; de Jesus, R. M.; da Rocha, G. O.; Ferreira, S. L. C.; de Andrade, J. B. Microchem. J. 2010, 96, 46. [CrossRef]

${ }^{13}$ da Rocha, G. O.; Lopes, W. A.; Pereira, P. A. P.; Vasconcellos, P. C.; Oliveira, F. S.; Carvalho, L. S.; Conceição, L. S.; de Andrade, J. B. J. Braz. Chem. Soc. 2009, 20, 680. [CrossRef]
${ }^{14}$ Pereira, P. A. P.; Lopes, W. A.; Carvalho, L. S.; da Rocha, G. O.; Bahia, N. C.; Loyola, J.; Quitério, S. L.; Escaleira, V.; Arbilla, G.; de Andrade, J. B. Atmos. Environ. 2007, 41, 7837. [CrossRef]

${ }^{15}$ Grosjean, D.; Miguel, A. H.; Tavares, T. M. Atmos. Environ. 1990, 24, 101. [CrossRef]

${ }^{16}$ Tavares, T. M.; Rocha, V. C.; Nogueira, E. M.; Grieken, V.; Klockow, D. Rev. Int. Cont. Ambient. 1993, 9, 50.

${ }^{17}$ Ferreira, S. L. C.; Macedo, S. M.; dos Santos, D. C.; Jesus, R. M.; dos Santos, W. N. L.; Queiroz, A. F. S.; de Andrade, J. B.; J. Anal. At. Spectrom. 2011, 26, 1887. [CrossRef]

${ }^{18}$ Toledo, V. E.; de Almeida Jr., P. B.; Quiterio, S. L.; Arbilla, G.; Morreira, A.; Escaleira, V.; Moreira, J. C. Environ. Monit. Assess. 2008, 139, 49. [CrossRef] [PubMed]

${ }^{19}$ Loyola, J.; de Almeida Jr., P. B.; Quiterio, S. L.; Sousa, C. R.; Arbilla, G.; Escaleira, V.; de Carvalho, M. I.; da Silva, A. S. A. G. Arch. Environ. Contam. Toxicol. 2006, 51, 485. [CrossRef] [PubMed]

${ }^{20}$ Arruti, A.; Fernández-Olmo, I.; Irabien, A. Atmos. Res. 2011, 101, 280. [CrossRef]

${ }^{21}$ Park, K.; Dam, H. D. Environ. Monit. Assess. 2010, 160, 289. [CrossRef]

${ }^{22}$ Kong, S.; Han, B.; Bai, Z.; Chen, L.; Shi, J.; Xu, Z. Sci. Total Environ. 2010, 408, 4681. [CrossRef]

${ }^{23}$ Heal, M. R.; Hibbs, L. R.; Agius, R. M.; Beverland, I. J. Atmos. Environ. 2005, 39, 1417. [CrossRef]

${ }^{24}$ Allen, A. G.; da Rocha, G. O.; Cardoso, A. A.; Paterlini, W. C.; Machado, C. M. D.; de Andrade, J. B. Transportation Research Part D: Transport and Environment 2008, 13, 483. [CrossRef]

${ }^{25}$ Guarieiro, A. L. N.; da Rocha, G. O.; Conceição, L. S.; Lopes, W. A.; Pereira, P. A. P.; de Andrade, J. B. Resumos da $32^{a}$ Reunião Anual da Sociedade Brasileira de Química, Fortaleza, Brasil, 2009.

${ }^{26}$ Lima, F. M.; Netto, A. D. P. J. Braz. Chem. Soc. 2009, 20, 488. [CrossRef] 
27 Azevedo, D. A.; Moreira, L. S.; de Siqueira, D. S. Atmos. Environ. 1999, 33, 4987. [CrossRef]

${ }^{28}$ Vasconcellos, P. C.; Zacarias, D.; Pires, M. A. F.; Pool, C. S.; Carvalho, L. R. F. Atmos. Environ. 2003, 37, 3009. [CrossRef]

29 Ding, X.; Wang, X. -M.; Xie, Z. -Q.; Xiang, C. -H.; Mai, B. -X.; Sun, L. -G.; Zheng, M.; Sheng, G. -Y.; Fu, J. -M.; Poschl, U. Atmos. Environ. 2007, 41, 2061. [CrossRef]

${ }^{30}$ Vasilakos, C.; Levi, N.; Maggos, T.; Hatzianestis, J.; Michopoulos, J.; Helmis, C. J. Hazard. Mater. 2007, 140, 45. [CrossRef] [PubMed]

${ }^{31}$ UNEP/IOC/IEAEA. Em Determination of petroleum hydrocarbons in sediments. Reference Methods for Marine Pollution Studies, n. 20. United Nations Environment Programme, Intergovernmental Oceanographic Commission and International Atomic Energy Agency. 1992.

32 Horowitz, A. J.; Primer on trace metalsediment chemistry. 2a. ed., United States Government Printing Office: Alexandria, 1991.

${ }^{33}$ Hatje, V.; Barros, F.; Figueiredo, D. G.; Santos, V. L. C. S.; Peso-Aguiar, M. C. Mar. Pollut. Bull. 2006, 52, 982. [CrossRef] [PubMed]

${ }^{34}$ Hatje, V.; Barros, F. C. R.; Riatto, V. B.; Resumos do $3^{\circ}$ Simpósio Brasileiro de Oceanografia, São Paulo, Brasil, 2006.

${ }^{35}$ CRA. Diagnóstico da concentração de metais pesados e hidrocarbonetos de petróleo nos sedimentos e biota da Baía de Todos os Santos. Consórcio BTS Hydros CH2MHILL. Governo do Estado da Bahia, 2004.

${ }^{36}$ Hatje, V.; Barros, F. Mar. Pollut. Bull. 2012, in press. [CrossRef] [PubMed]

${ }^{37}$ Barros, F.; Hatje, V.; Figueiredo, M. B.; Magalhães, W. F.; Dórea, H. S.; Emídio, E. S. Estuar. Coast. Shelf Sci. 2008, 78, 753. [CrossRef]
38 UFBA. Programa de monitoramento dos ecossistemas ao norte da Baía de Todos os Santos. Relatório Final. Salvador, Universidade Federal da Bahia, Tomo IX,1996.

${ }^{39}$ CRA. Resultado das análises: água $e$ sedimentos na BTS. Relatório Técnico. Governo do Estado da Bahia, 1997.

${ }^{40}$ CRA. Inventário de atividades com potencial de contaminação/ poluição e de produtos químicos na Baía de Todos os Santos. Tomo I - Relatório, 2008.

${ }^{41}$ Alves, T. C. A. Dissertação de Mestrado, Universidade Federal da Bahia, Brasil, 2002. [Link]

42 Queiroz, A. F.; Celino, J. J. Em Avaliação de Ambientes na Baía de Todos os Santos: aspectos geoquímicos, geofísicos e biológicos; A. F.; Celino, J. J., eds.; PROAMB, UFBA: Salvador, 2008, cap. 1.

${ }^{43}$ Carvalho, F.; Tavares, T. M.; Souza, S. P.; Linhares, P. S. Environ. Res., 1984, 33, 300. [CrossRef]

${ }^{44}$ Carvalho F. M.; Silvany-Neto, A. M.; Tavares, T. M.; Lima, M. E.; Waldron, H. A. Bull. Pan. Am. Health Organ. 1985, 19, 165. [PubMed]

${ }^{45}$ Carvalho, F. M.; Silvany-Neto, A. M.; Melo, A. M. C.; Chaves, M. E. C.; Brandão, A. M.; Tavares, T. M. Sci. Total Environ. 1989, 84, 119. [CrossRef]

${ }^{46}$ CRA. Resultado das análises: água $e$ sedimentos na BTS. 1987/1992/1993/1994/1995/1996. Relatório Técnico. Governo do Estado da Bahia, 1996.

${ }^{47}$ Wasserman, J. C.; Queiroz, E. L. Quim. Nova. 2004, 27, 17. [CrossRef]

${ }^{48}$ Hatje, V.; Macedo, S. M.; de Jesus, R. M.; Cotrim, G.; Garcia, K. S.; de Queiroz, A. F.; Ferreira, S. L. C. Mar. Pollut. Bull. 2010, 60, 2225. [CrossRef] [PubMed]

${ }^{49}$ Barbosa, M. C.; de Almeida, M. S. S.; Mariz, D. F.; de Almeida, J. L. D. S. S. J. Hazard. Mater. 2004, 110, 29. [CrossRef]_[PubMed] 
${ }^{50}$ Batista-Neto, J. A.; Gingele, F. X.; Leipe, T.; Brehme, I. Environ. Geol. 2006, 49, 1051. [CrossRef]

${ }^{51}$ Batista Neto, J. A.; Crapez, M.; McAlister, J. J.; Vilela, C. G. J. Coast. Res. 2005, 21, 811. [CrossRef]

${ }^{52}$ Gomes, F. C.; Godoy, J. M.; Godoy, M. L. D. P.; de Carvalho, Z. L.; Lopes, R. T.; SanchezCabeza, J. A.; de Lacerda, L. D.; Wasserman, J. C. Mar. Pollut. Bull. 2009, 59, 123. [CrossRef] [PubMed]

${ }^{53}$ Luiz-Silva, W.; Matos, R. H. R.; Kristosch, G. C.; Machado, W. Quim. Nova 2006, 29, 256. [CrossRef]

${ }^{54}$ Bordon, I. C. A. C.; Sarkis, J. E. S.; Gobbato, G. M.; Hortellani, M. A.; Peixoto, C. M. J. Braz. Chem. Soc. 2011, 22, 1858. [CrossRef]

${ }^{55}$ Buruaem, L. M.; Hortellani, M. A.; Sarkis, J. E.; Costa-Lotufo, L. V.; Abessa, D. M. S. Mar. Pollut. Bull. 2012, 64, 479. [CrossRef]

${ }^{56}$ Tavares, T. M.; Rocha, V. C.; Porte, C.; Barceló, D.; Albaigés, J. Mar. Pollut. Bull. 1988, 19, 575. [CrossRef]

${ }^{57}$ BMA (Biomonitoramento e Meio Ambiente). Diagnóstico ambiental dos manguezais situados no Estuário do Rio Caípe, Bahia. Relatório Final, 2002.

${ }^{58}$ Vondráček, J.; Švihálková-Šindlerová, L.; Pêncíková, K.; Marvanová, S.; Krčmář, P.; Ciganek, M.; Neca, J.; Trosko, J. E.; Upham, B.; Kozubík, A.; Machala, M. Environ. Toxicol. Chem. 2007, 26, 2308. [CrossRef] [PubMed]

${ }^{59}$ Baird, S. J. S.; Bailey, E. A.; Vorhees, D. J. Hum. Ecol. Risk Assess. 2007, 13, 322. [CrossRef]

${ }^{60}$ Bícego, M. C.; Taniguchi, S.; Yogui, G. T.; Montone, R. C.; da Silva, D. A. M.; Lourenço, R. A.; Martins, C. C.; Sasaki, S. T.; Pellizari, V. H.; Weber, R. R. Mar. Pollut. Bull. 2006, 52, 1804. [CrossRef] [PubMed]

${ }^{61}$ Zheng, G. J.; Richardson, B. J. Chemosphere 1999, 38, 2625. [CrossRef]

${ }^{62}$ Venturini, N.; Tommasi, L. R.; Bícego, M. C.; Martins, C. C. Braz. J. Oceanogr. 2004, 52, 123. [CrossRef]
${ }^{63}$ Venturini, N.; Muniz, P.; Bícego, M. C.; Martins, C. C.; Tommasi, L. R. Estuar. Coast. Shelf Sci. 2008, 78, 457. [CrossRef]

${ }^{64}$ Celino, J. J.; Queiroz, A. F. S. REM: Rev. Esc. Minas 2006, 59, 265. [CrossRef]

${ }^{65}$ SENAI. Diagnóstico ambiental do manguezal na foz do Rio Caípe, São Francisco do Conde - Bahia. Relatório Final, 2006.

${ }^{66}$ Medeiros, P. M.; Bícego, M. C. Mar. Pollut. Bull. 2004, 49, 761. [CrossRef] [PubMed]

${ }^{67}$ Muniz, P.; Danulat, E.; Yannicelli, B.; García-Alonso, J.; Medina, G.; Bícego, M. C. Environ. Int. 2004, 29, 1019. [CrossRef]

${ }^{68}$ Readman, J. W.; Fillmann, G.; Tolosa, I.; Bartocci, J.; Villeneuve, J. -P.; Catinni, C.; Mee, L. D. Mar. Pollut. Bull. 2002, 44, 48. [CrossRef]

${ }^{69}$ Evangelista, A. J. A.; Nascimento, I. A.; Pereira, S. A.; Lopes, M. B. N.L.; Martins, L. K. P.; Fillmann, G. Ciênc. Mar. 2005, 31, 43.

${ }^{70}$ Kim, G. B.; Maruya, K. A.; Lee, R. F.; Lee, J. H.; Koh, C. -H.; Tanabe, S. Mar. Pollut. Bull. 1999, 38, 7. [CrossRef]

${ }^{71}$ Soclo, H. H.; Garrigues, P.; Ewald, M. Mar. Pollut. Bull. 2000, 40, 387. [CrossRef]

72 McLeroy, A. E.; Farrington, J. W.; Teal, J. M.; Metabolism of polycyclic aromatic hydrocarbons in the aquatic environment, CRC Press: Boca Raton, 1989.

${ }^{73}$ Farrington, J. W.; Frew, N. M.; Geshwend, P. M.; Tripp, B. W. Estuar. Coast. Shelf Sci. 1977, 5, 793. [CrossRef]

${ }^{74}$ Volkman, J. K.; Holdsworth, D. G.; Neil, G. P.; Bavor Jr., H. J. Sci. Total Environ. 1992, 112, 203. [CrossRef]

${ }^{75}$ Cox, R. E.; Mazurek, M. A.; Simoneit, B. R. T. Nature 1982, 296, 848. [CrossRef]

${ }^{76}$ Rainbow, P. S.; Em Ecotoxicology of metals in invertebrates; Dallinger, R.; Rainbow. P. S., Eds.; Lewis Publishers: Chelsea, 1993, cap. 1.

${ }^{77}$ Cantillo, A. Y. Mar. Pollut. Bull. 1998, 36, 712. [CrossRef]

${ }^{78}$ Chiffoleau, J. -F.; Auger, D.; Roux, N.; Rozuel, E.; Santini, A. Mar. Pollut. Bull. 2005, 50, 1719. [CrossRef] [PubMed]

${ }^{79}$ Lauenstein, G. G.; Robertson, A.; O'Connor, T. P. Mar. Pollut. Bull. 1990, 21, 440. [CrossRef]

${ }^{80}$ Silva, C. A. R.; Smith, B. D.; Rainbow, P. S. Mar. Environ. Res. 2006, 61, 439. [CrossRef] 
${ }^{81}$ CRA. Análise preliminar de risco à saúde humana. Relatório síntese. Consórcio BTS Hydros CH2MHILL. Governo do Estado da Bahia, 2005.

${ }^{82}$ Freitas, H.; Guedes, M. L. S.; Smith, D. H.; Oliveira, S. S.; Santos, E. S.; da Silva, E. M. Aquat. Ecosyst. Health Mgmt. 2002, 5, 217. [CrossRef]

${ }^{83}$ Garcia, K. S.; de Oliveira, O. M. C.; de Araujo, B. R. N.; Avaliação de Ambientes na Baía de Todos os Santos; PROAMB UFBA: Salvador, 2008.

${ }^{84}$ de Souza, M. M.; Windmöller, C. C.; Hatje, V. Mar. Pollut. Bull. 2011, 62, 2254. [CrossRef]_[PubMed]

${ }^{85}$ Peso-Aguiar, M. C.; Verani, J. R. Verh. Internat. Verein. Liminol. 1998, 26, 2015.

${ }^{86}$ Wallner-Kersanach, M.; Theede, H.; Eversberg, U.; Lobo. S. Arch. Environ. Contam. Toxicol. 2000, 38, 40. [CrossRef] [PubMed]

${ }^{87}$ Gonçalves, R. S. L. Dissertação de Mestrado, Universidade Federal do Ceará, Brasil, 2006. [Link]
${ }^{88}$ Amado-Filho, G. M.; Salgado, L. T.; Rebelo, M. F.; Rezende, C. E.; Karez, C. S.; Pfeiffer, W. C. Braz. J. Biol. 2008, 68, 95. [CrossRef]

${ }^{89}$ Alves, A. M.; Moura, C. W. N.; Alves, G. L.; Gestinari, L. M. S. Rev. Bras. Bot. 2009, 32, 545. [CrossRef]

${ }^{90}$ Alves, A. M.; Gestinari, L. M. S.; Moura, C. W. N. Bot. Mar. 2011, 54, 135. [CrossRef]

${ }^{91}$ Amado Filho, G. M.; Karez, C. S.; Andrade, L. R.; Yoneshigue-Valentin, Y.; Pfeiffer, W. C., Ecotoxicol. Environ. Saf. 1997, 37, 223. [CrossRef]

${ }^{92}$ Brito, G. B.; de Souza, T. L.; Bressy, F. C.; Moura, C. W. N.; Korn, M. G. A. Mar. Pollut. Bull. 2012, 64, 2238. [CrossRef] [PubMed]

${ }^{93}$ Amado-Filho, G. M.; Salgado, L. T.; Rebelo, M. F.; Rezende, C. E.; Karez, C. S.; Pfeiffer, W. C. Braz. J. Biol. 2008, 68, 95. [CrossRef]

94 Vidotti, E. C., Rollemberg, M. C. E. Quim. Nova 2004, 27, 139. [CrossRef] 